\title{
Influence of Dry Milling on Phase Transformation of Sepiolite upon Alkali Activation: Implications for Textural, Catalytic and Sorptive Properties
}

\author{
Anna Walczyk ${ }^{1}$, Robert Karcz ${ }^{1}{ }^{1}$, Joanna Kryściak-Czerwenka ${ }^{1}$, Bogna D. Napruszewska ${ }^{1}$, \\ Dorota Duraczyńska $^{1}$, Alicja Michalik ${ }^{1}$, Zbigniew Olejniczak ${ }^{2}$, Anna Tomczyk ${ }^{3}{ }^{(D)}$, \\ Agnieszka Klimek ${ }^{3}$ (D), Krzysztof Bahranowski ${ }^{3, *}$ and Ewa M. Serwicka ${ }^{1, *(D)}$ \\ 1 Jerzy Haber Institute of Catalysis and Surface Chemistry, Polish Academy of Sciences, Niezapominajek 8, \\ 30-239 Krakow, Poland; ncawalcz@cyf-kr.edu.pl (A.W.); nckarcz@cyf-kr.edu.pl (R.K.); \\ nckrysci@cyf-kr.edu.pl (J.K.-C.); ncnaprus@cyf-kr.edu.pl (B.D.N.); ncduracz@cyf-kr.edu.pl (D.D.); \\ ncmichal@cyf-kr.edu.pl (A.M.) \\ 2 Institute of Nuclear Physics, Polish Academy of Sciences, Radzikowskiego 152, 31-342 Krakow, Poland; \\ zbigniew.olejniczak@ifj.edu.pl \\ 3 AGH University of Science and Technology, Faculty of Geology, Geophysics and Environmental Protection, \\ al. Mickiewicza 30, 30-059 Krakow, Poland; tomczyk.an@gmail.com (A.T.); agaklimek@o2.pl (A.K.) \\ * Correspondence: bahr@agh.edu.pl (K.B.); ncserwic@cyf-kr.edu.pl (E.M.S.); Tel.: +48-12-617-2379 (K.B.); \\ +48-12-6395-118 (E.M.S.)
}

Received: 28 July 2020; Accepted: 3 September 2020; Published: 5 September 2020

\begin{abstract}
Activation of natural sepiolite by means of grinding in a planetary mill followed by wet $\mathrm{NaOH}$ activation was studied for the purpose of endowing the product with enhanced basicity for potential catalytic/sorptive applications. Synthesized solids were characterized with X-ray powder diffraction (XRD), $\mathrm{N}_{2}$ adsorption/desorption, scanning electron microscopy (SEM), energy dispersive (EDX), atomic absorption (AAS), Fourier-transform infrared (FTIR) and ${ }^{29}$ Si magic angle spinning nuclear magnetic resonance (MAS NMR) spectroscopies. Surface basicity was determined by titration with benzoic acid. Grinding changed the pathway of sepiolite phase transformation upon $\mathrm{NaOH}$ treatment. The as-received sepiolite evolved to Na-sepiolite (loughlinite) with a micropore system blocked by nanocrystalline $\mathrm{Mg}(\mathrm{OH})_{2}$, while ground samples yielded magnesium silicate hydrate phase (MSH), with well-developed microporous texture. In unmilled sepiolite desilication involved preferential leaching of $\mathrm{Si}$ from the center of the structural ribbons, while in ground samples additional loss of $\mathrm{Si}$ from ribbon-ribbon corner linkages was observed. In all cases treatment with $\mathrm{NaOH}$ led to enhancement of surface basicity. Synthesized materials were tested as catalysts in a base-catalyzed aldol self-condensation of acetone and oxidation of cyclohexanone to $\varepsilon$-caprolactone, as well as $\mathrm{CO}_{2}$ sorbents. Catalytic trends depended not only on samples' basicity, but also on texture and phase composition of the catalysts. Grinding combined with alkali activation proved a simple and effective method for boosting $\mathrm{CO}_{2}$-sorption capacity of sepiolite to the level comparable to amine-functionalized, acid-activated sepiolite sorbents.
\end{abstract}

Keywords: sepiolite; grinding; alkali activation; loughlinite; magnesium silicate hydrate; basicity; aldol condensation; Baeyer-Villiger oxidation; $\mathrm{CO}_{2}$ sorption

\section{Introduction}

Grinding of clay minerals is a very common treatment used both at the industrial scale and in research laboratories. Usually the primary goal is the reduction of particle size, but the treatments are known to induce significant changes in other physico-chemical properties of the mineral, by affecting 
its structure, texture and chemical reactivity [1,2]. Understanding of these phenomena is essential for different technological applications of clays, such as e.g., engineering of materials for adsorption and catalysis, preparation of mineral fillers, ceramic industry, agriculture, pharmacology, cosmetology, etc. Another type of modification of clay mineral is activation with acid or base, in order to selectively leach basic or acidic elements, respectively [3,4]. Such treatment modifies the mineral porosity by creating voids within the clay lattice, and endows the material with enhanced acid or base properties, factors of crucial importance for applications in catalysis and sorption. As shown in the recent review by Komadel [3], very many reports deal with acid-activated clays, with much fewer addressing the alkali-treated clays [4]. The latter, however, gain rapidly on importance, due their potential as base catalysts for valorization of biomass in the most common transesterification process [5], or as alkaline adsorbents favoring capture of acidic $\mathrm{CO}_{2}$ molecules [6]. Clays are cheap, abundant and environmentally benign materials, thus offer the possibility of developing low-cost, eco-friendly catalysts and adsorbents. Most of the research into basic clay-derived materials focuses on the alkali-modified montmorillonite, the main component of bentonite rocks, and the most widely investigated clay mineral [7-10]. However, we have recently pointed out that for the purpose of developing solids with basic functionality, magnesium-rich clay minerals, with stronger intrinsic basicity, such as e.g., sepiolite, are especially suited [11,12].

Sepiolite is a hydrated magnesium silicate with fibrous morphology, of theoretical unit cell formula $\mathrm{Mg}_{8}\left(\mathrm{H}_{2} \mathrm{O}\right)_{4}(\mathrm{OH})_{4}\left[\mathrm{Si}_{12} \mathrm{O}_{30}\right] \cdot \mathrm{nH}_{2} \mathrm{O}(\mathrm{n} \leq 8)$ [13]. The structure of sepiolite, shown in Figure 1 , consists of 2:1 phyllosilicate ribbon-like blocks, corner-linked to each other by Si-O-Si bonds joining inverted $\mathrm{SiO}_{4}$ tetrahedra from neighboring ribbons. Such an arrangement results in structural tunnels with an effective cross-section of $10.6 \times 3.7 \AA$ [14-17], which are the reason for the microporosity and high specific surface area of sepiolite. Each terminal $\mathrm{Mg}$ site at the ribbon edge coordinates two water molecules, protruding into the tunnels. In addition, tunnels are filled with zeolitic water. Some $\mathrm{Al}(\mathrm{Fe})$ for Si substitution in the tetrahedral sheet, and $\mathrm{Al}(\mathrm{Fe})$ for $\mathrm{Mg}$ substitution in the octahedral sheet may occur in natural sepiolite and generate certain ion exchange capacity.

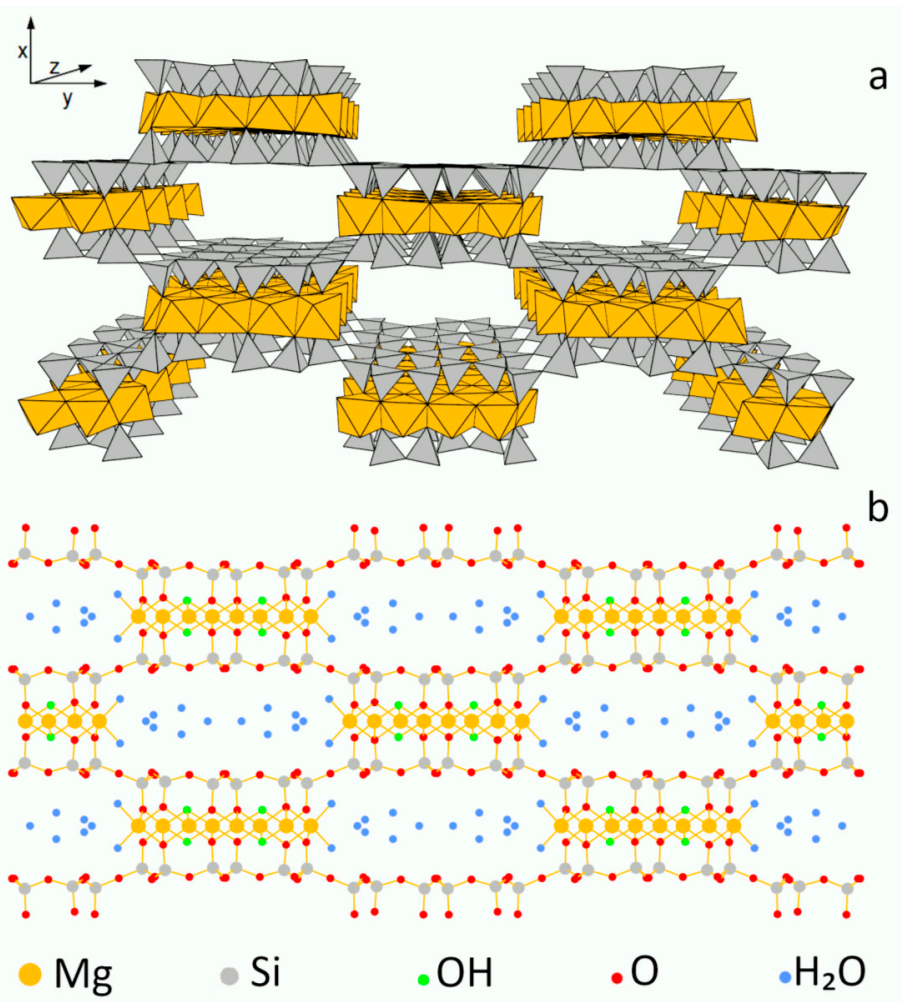

Figure 1. Model of sepiolite structure: (a) polyhedral, (b) ball and stick. 
We have shown that treatment of sepiolite with aqueous solution of $\mathrm{NaOH}$ is an easy tool for tailoring the materials' basicity, and associated catalytic (acetone self-condensation, and cyclohexanone oxidation) and sorptive $\left(\mathrm{CO}_{2}\right)$ properties [12]. Upon alkali activation a gradual transformation of sepiolite into partially desilicated Na-sepiolite (loughlinite) occurred, accompanied by intraporous formation of magnesium hydroxide nanoparticles. The latter was found to be the main factor responsible for the enhancement of basicity-related surface properties.

Studies on Mg-bearing natural minerals and synthetic hydrotalcites have proved that mechanical grinding, when appropriately optimized, may also serve as means to enhance performance of basic catalysts, mainly due to the decrease of the catalyst crystal size [11,13]. Therefore, in the search for further means of improvement of the sepiolite catalytic/sorptive properties, the effect of grinding pretreatment in a planetary mill on the efficiency of the alkali activation of this mineral was investigated in the present work. Grinding of sepiolite has been addressed in several reports [18-22]. Generally, the treatment was found to result in the breakage of sepiolite fibers, loss of crystallinity and decrease of the specific surface area. Upon long-grinding a complete destruction of fiber morphology and structure amorphization was observed. However, the joint operation of both treatments, i.e., alkali activation and grinding, as well as their effect on catalytic and sorptive properties of sepiolite, have not been, as yet, described in the literature.

The focus of this study is the effect of combined alkali and grinding pretreatment on the evolution of sepiolite structural and surface properties, in particular basicity, important for potential applications in catalysis and sorption. Base-catalyzed aldol self-condensation of acetone and oxidation of cyclohexanone to $\varepsilon$-caprolactone were chosen as test reactions. $\mathrm{CO}_{2}$ uptake, favored by the adsorbent alkalinity, was also investigated. Results were referred to the performance of an untreated sepiolite.

\section{Materials and Methods}

\subsection{Materials}

Commercial sepiolite provided by Tolsa SA (Madrid, Spain), referred to as Sep, was used as the parent material. Grinding of sepiolite was carried out with aid of the planetary mono mill PULVERISETTE 6 (Fritsch, Idar-Oberstein, Germany) (600 rpm, with $4 \mathrm{~g}$ sample batches, using twenty-four 10-mm-diameter silicon nitride balls). The applied grinding times were 10, 30 and $60 \mathrm{~min}$. For each grinding time, a new portion of the parent sepiolite was used. The millings lasting $\geq 10$ min were performed in 15 min intervals, with a 10-min break between the grinding periods. Wet alkali activation consisted of treatment of sepiolite powder with a $2 \mathrm{M} \mathrm{NaOH}$ (Sigma-Aldrich, Saint Louis, MO, USA, reagent grade) solution $(1 \mathrm{~g} / 100 \mathrm{~mL})$, upon vigorous mixing, at $90^{\circ} \mathrm{C}$, for 3 or $24 \mathrm{~h}$. The recovered alkali-treated sepiolite samples were washed 5 times by dispersing in distilled water followed by centrifugation, and dried at $50^{\circ} \mathrm{C}$. The samples are denoted Sep/gr-time/NaOH-time, thus indicating the duration of grinding and the duration and temperature of alkaline treatment. For instance, sample signature Sep/gr-30'/NaOH-3h, means sepiolite ground for 30 minutes and treated with hot $\left(90^{\circ} \mathrm{C}\right) \mathrm{NaOH}$ solution for 3 hours. In addition, a sample of brucite, $\mathrm{Mg}(\mathrm{OH})_{2}$, was prepared by precipitation at $\mathrm{pH}=10$ from aqueous solutions of $\mathrm{Mg}\left(\mathrm{NO}_{3}\right)_{2}$ and $\mathrm{NaOH}$. All chemicals used in materials' syntheses, adsorption and catalytic experiments were reagent grade, purchased from Sigma-Aldrich.

\subsection{Methods of Physico-Chemical Characterization}

Powder X-ray diffraction patterns were recorded with X'Pert PRO MPD (PANalytical, Almelo, The Netherlands) diffractometer, using $\mathrm{Cu} \mathrm{K} \alpha$ radiation $(40 \mathrm{kV}, 30 \mathrm{~mA})$, a flat graphite monochromator in the diffracted beam and a step size of $0.0334^{\circ}$. The setup included a programmable automated divergence slit giving a constant, illuminated sample length of $10 \mathrm{~mm}$. 
Scanning electron microscopy-energy dispersive X-ray spectroscopy (SEM/EDX) analysis was carried out with aid of JEOL JSM-7500F (JEOL, Tokyo, Japan) coupled with an INCA PentaFetx3 EDX (Oxford Instruments, Abingdon, UK) system. SEM images were recorded for the uncoated samples deposited on 200 mesh copper grids covered with carbon support film.

The amount of $\mathrm{Mg}$ and $\mathrm{Si}$ leached to the solution upon alkali activation of sepiolite samples was determined by atomic absorption spectrometry method, using Thermo Scientific 3500 (Thermo Electron Manufacturing, Cambridge, UK) equipment.

$\mathrm{N}_{2}$ adsorption/desorption at $-196^{\circ} \mathrm{C}$ was measured with an AUTOSORB 1 (Quantachrome, Boynton Beach, FL, USA) instrument. The samples were outgassed at $120^{\circ} \mathrm{C}$ for $20 \mathrm{~h}$. BET formalism was used for the calculation of specific surface areas, and a t-plot was used for the micropore surface area $\left(\mathrm{S}_{\text {micro }}\right)$ and micropore volume $\left(\mathrm{V}_{\text {micro }}\right)$ evaluation. The total pore volume $\left(\mathrm{V}_{\text {tot }}\right)$ was determined from the amount of $\mathrm{N}_{2}$ adsorbed at $\mathrm{p} / \mathrm{p}_{0}=0.996$. The mean pore diameter $\left(\mathrm{D}_{\mathrm{av}}\right)$ was calculated with the $\mathrm{D}_{\mathrm{av}}=4 \mathrm{~V}_{\text {tot }} / \mathrm{S}_{\mathrm{BET}}$ formula.

Fourier transform infrared (FTIR) absorption spectra in middle infrared were recorded using transmission mode with a Nicolet 6700 (Thermo Scientific, Madison, WI, USA) spectrometer, in the $4000-400 \mathrm{~cm}^{-1}$ range. Samples were prepared as KBr pellets-64 scans at $2 \mathrm{~cm}^{-1}$ resolution were taken for each sample.

The solid state ${ }^{29}$ Si MAS NMR spectra were measured on the APOLLO console (Tecmag Inc., Houston, TX, USA) at the magnetic field of $7.05 \mathrm{~T}$ provided by the $300 \mathrm{MHz} / 89 \mathrm{~mm}$ superconducting magnet (Magnex Scientific, Abingdon, UK). A Bruker HP-WB high-speed MAS probe equipped with the $4 \mathrm{~mm}$ zirconia rotor and KEL-F cap was used to spin the sample at $4 \mathrm{kHz}$. The resonance frequency was equal to $59.515 \mathrm{MHz}$, and a single $3 \mu \mathrm{s}$ rf excitation pulse corresponding to a $\pi / 2$ flipping angle was applied. The number of averages was 512 , with the acquisition delay equal to $30 \mathrm{~s}$. The frequency scale in ppm was referenced to tetramethylsilane (TMS).

Basicity of the materials was determined from the amount of benzoic acid (BA) adsorbed at room temperature $(\mathrm{pKa}=4.19)$, as a mean of three experiments \pm standard error. Briefly, $0.01 \mathrm{~g}$ of the sample was dispersed in $10 \mathrm{~mL}$ of BA solution in cyclohexane and mixed for $3 \mathrm{~h}$. Then the solid was centrifuged and the concentration of BA remaining in the solution was determined by recording UV-vis absorption spectra with a Shimadzu UV 160A (Shimadzu, Kyoto, Japan) spectrophotometer, using quartz cells of $1 \mathrm{~cm}$ optical path.

\subsection{Catalytic Testing}

Aldol self-condensation of acetone to diacetone alcohol (DAA) was used as a model base-catalyzed reaction. The reaction was performed for $3 \mathrm{~h}$ in thermostated glass batch reactors using Radleys Carousel 6 parallel reaction station (Radleys, Shire Hill, Saffron Walden, Essex, UK) with a magnetic stirrer (500 rpm), at $40{ }^{\circ} \mathrm{C}$, using $0.03 \mathrm{~g}$ of the as-received dried sample as a catalyst and $5 \mathrm{~mL}$ of acetone. It was found that beyond $500 \mathrm{rpm}$ the agitation speed had no effect on the rate of reaction. The reaction mixture was analyzed by gas chromatography using a Thermo Trace GC Ultra instrument (Thermo Electron Corporation, Austin, TX, USA) fitted with a TR- 5 column with a flame ionization detector. Yield of DAA was determined as a mean value of the product from three reaction runs performed at the same conditions, \pm standard error. Samples were withdrawn from the reaction mixture after fixed time and analyzed as described.

Base-catalyzed, mild oxidation of cyclohexanone to $\varepsilon$-caprolactone in the recently described $\mathrm{H}_{2} \mathrm{O}_{2} /$ nitrile/bicarbonate system [23] was carried out for $3 \mathrm{~h}$ at $70{ }^{\circ} \mathrm{C}$ in a glass reactor using Radleys Carousel 6 parallel reaction station (Radleys, Shire Hill, Saffron Walden, Essex, UK), with magnetic stirring (500 rpm), using $0.06 \mathrm{~g}$ of catalyst, $6 \mathrm{mmol}$ of cyclohexanone, $50 \mathrm{mmol}$ of $30 \% \mathrm{H}_{2} \mathrm{O}_{2}, 0.1 \mathrm{mmol}$ of $\mathrm{NaHCO}_{3}$ and $100 \mathrm{mmol}$ of acetonitrile solvent. Increasing the stirring speed beyond $500 \mathrm{rpm}$ had no effect on the rate of reaction. The reaction mixture was analyzed by gas chromatography using a Thermo Trace GC Ultra (Thermo Electron Corporation, Austin, TX, USA) instrument fitted with a TR-5 capillary column and a flame ionization detector. Identification of by-products was performed using GC-MS analysis with the same GC equipped with a TR-5-MS capillary column and a DSQ II mass 
detector (Thermo Electron Corporation, Austin, TX, USA). Yield of $\varepsilon$-caprolactone was determined as a mean value of the product from three parallel runs performed at the same reaction conditions, \pm standard error. Samples were withdrawn from the reaction mixture after a fixed time and analyzed as described.

\subsection{Sorption of $\mathrm{CO}_{2}$}

Carbon dioxide sorption capacity was determined from $\mathrm{CO}_{2}$ isotherms obtained with a Micromeritics ASAP 2020 (Micromeritics, Norcross, GA, USA) analyzer at $0^{\circ} \mathrm{C}$, using ca. $300 \mathrm{mg}$ of the sorbent, in a pressure range from 0.2 to $760 \mathrm{~mm} \mathrm{Hg}$. Prior to the measurements, samples were outgassed at $150^{\circ} \mathrm{C}$ for $12 \mathrm{~h}$. To get an estimate of the standard error of the measurement the $\mathrm{CO}_{2}$ sorption on the parent sepiolite was conducted twice.

\section{Results and Discussion}

\subsection{SEM Analysis}

The effect of grinding and wet alkali treatment on the morphology of sepiolite grains was studied with scanning electron microscopy and the micrographs are presented in Figure 2.

The parent sepiolite showed fibrous morphology typical for this mineral (Figure 2a). Grinding for $10 \mathrm{~min}$ resulted in breaking and disintegration of sepiolite fibers, but small individual particles still retained their elongated shape (Figure 2c). In samples subjected to longer grinding times (30 min -Figure 2e; $60 \mathrm{~min}$-Figure 2g) the elongated grains disappeared completely. Instead, aggregates of irregularly shaped, rounded particles were observed. The effect of re-aggregation upon prolonged grinding of solids has been known for a long time [24]. In a ball mill, the particles get very close to one another due to mechanical pressure and friction, which eventually leads to the cold welding at the contact points.

Comparison of SEM images recorded for the parent and ground sepiolite samples with those obtained for the counterparts subjected to alkaline treatment shows that most pronounced changes in morphology occurred during alkali activation of sepiolite subjected to prolonged grinding.

Thus, the parent sepiolite (Figure 2a) and the sample ground for $10 \mathrm{~min}$ (Figure 2c), after $24 \mathrm{~h}$ of treatment with $\mathrm{NaOH}$ solution at $90^{\circ} \mathrm{C}$, showed, generally, grains of quite similar morphology to that found in the starting materials, i.e., long fibers in the first case and much shorter, broken ones, in the other (Figure 2b,d, respectively). On the other hand, in materials ground for 30 and $60 \mathrm{~min}$ (Figure 2e, $\mathrm{g}$, respectively), alkali treatment brought about a qualitative change in morphology. Thus, in both samples grinding lead to the complete destruction of fibrous particles and formation of spherical agglomerates, more compact for the longer the grinding time. Upon alkali treatment a partial disintegration of agglomerates accompanied by formation of very thin particles with laminar morphology was observed (Figure 2f,h, respectively), suggesting a deep change in the nature of the investigated silicate material. 

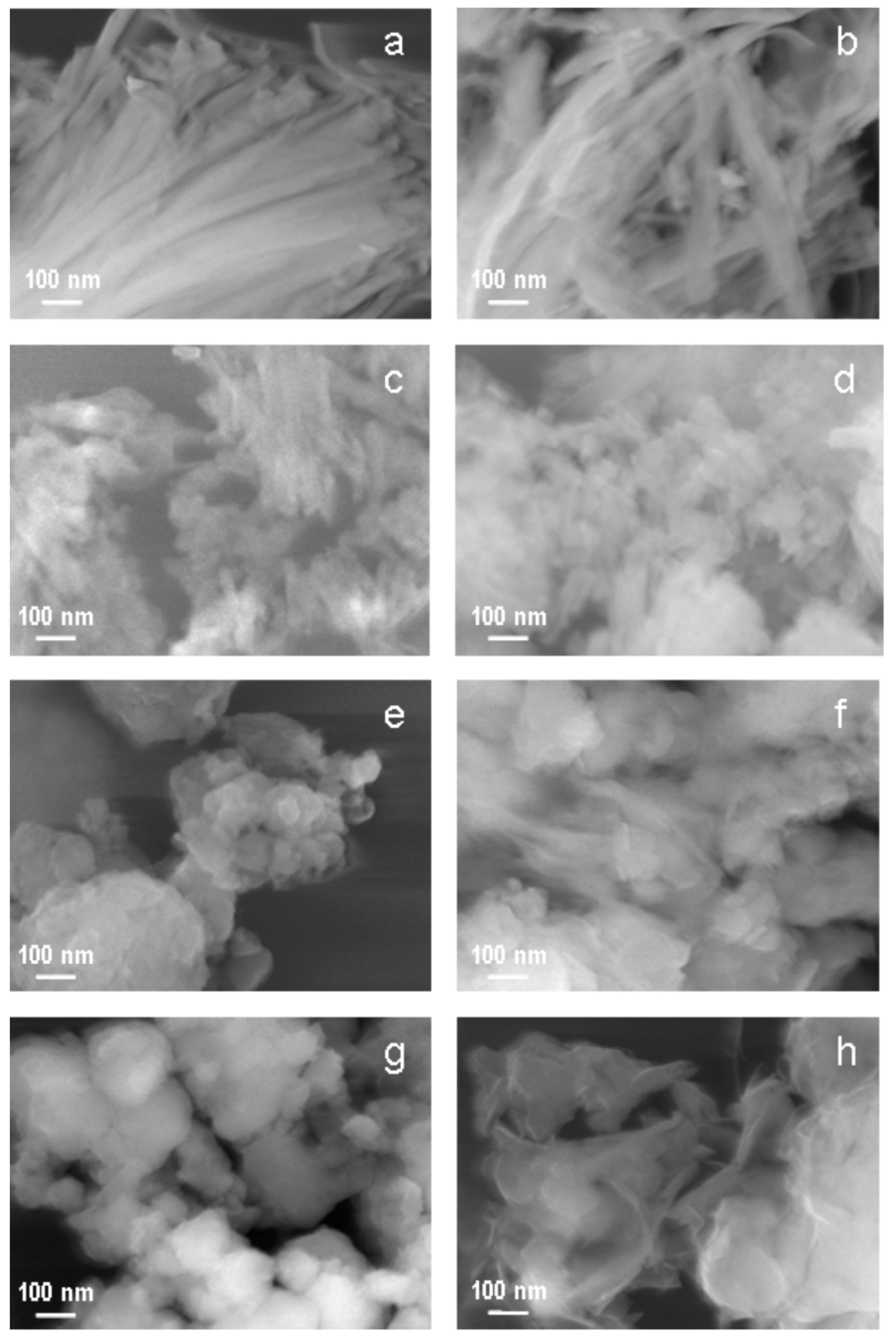

Figure 2. SEM images of: (a) Sep, (b) Sep/NaOH-24 h, (c) Sep/gr-10', (d) Sep/gr-10' $/ \mathrm{NaOH}-24$ h, (e) Sep/gr-30', (f) Sep/gr-30'/NaOH-24 h, (g) Sep/gr-60', (h) Sep/gr-60'/NaOH-24 h.

\subsection{XRD Analysis}

The parent material shows a characteristic X-ray diffraction pattern of sepiolite. The indexing, marked in Figure 3 (bottom), is based on the reported data (sepiolite, Ref. code 01-080-5781). Raw sepiolite also contains traces of quartz, calcite and dolomite impurities. The effect of grinding on the structure of sepiolite agreed, qualitatively, with the results reported by Cornejo and Hermosin [17]. As the grinding time increased, a gradual broadening of reflections belonging to sepiolite could be observed, attributable to the diminution of crystal size and growing crystal strain. The XRD pattern of the Sep/gr-60' sample indicated that the material underwent strong amorphization, as the 110 reflection of sepiolite, as well as other most intense reflections were barely marked. The reflections belonging to quartz and dolomite were still visible, although the latter was clearly broadened, while crystalline 
calcite could not be detected any more. Thus, the susceptibility of sepiolite and its impurities to grinding reflected the general trend of the minerals' hardness according to Mohs scale (sepiolite-2-2.5, calcite-3, dolomite-3.5-4, quartz-7) [25].

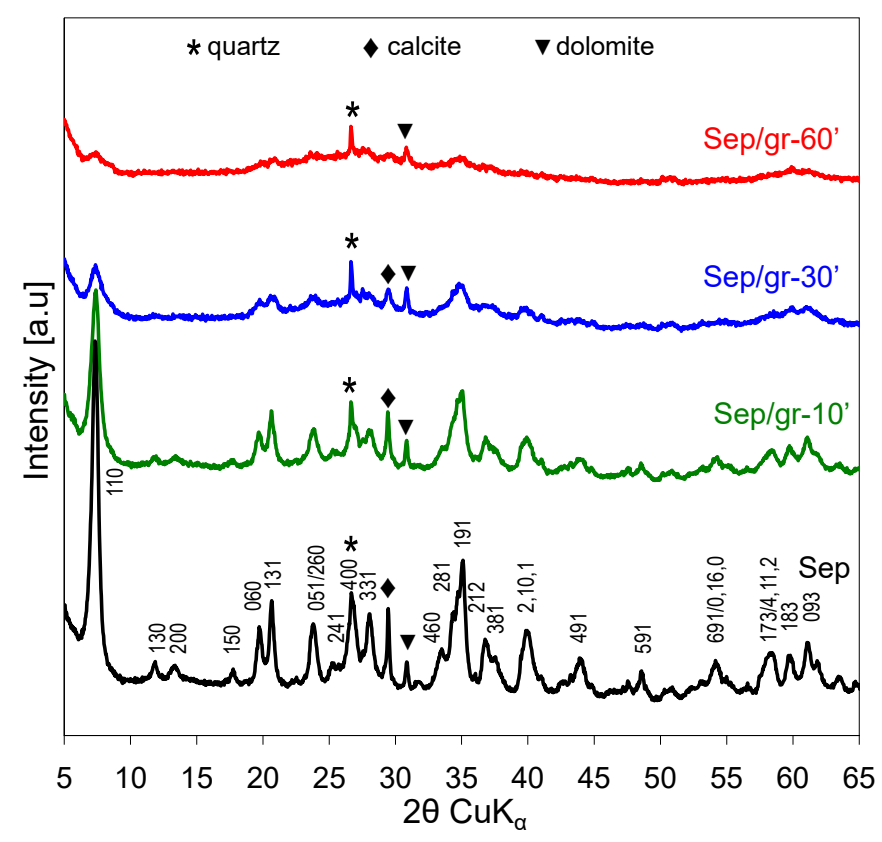

Figure 3. Effect of grinding on XRD patterns of sepiolite.

Evolution of XRD patterns of the as-received and ground sepiolite samples upon treatment with $\mathrm{NaOH}$ at $90^{\circ} \mathrm{C}$ for 3 or $24 \mathrm{~h}$ are illustrated in Figure 4.

As reported earlier [12], in the case of an untreated sepiolite the observed changes pointed to the gradual transformation of sepiolite into its sodium form, loughlinite (Figure 4a). The structural modification was directly evidenced by the shift of the (110) reflection towards higher $2 \theta$. The effect corresponded to the increase of $\mathrm{d}_{110}$ from $12.0 \AA$ observed for the starting sepiolite to ca. $12.7 \AA$ for the sample subjected to alkali treatment, the value characteristic of loughlinite (reference code 01-082-8023). The $\mathrm{NaOH}$ activation also affected the reflections of crystalline carbonate impurities. The most intense line of dolomite ceased to be visible and that of calcite diminished significantly. Additionally in the case of sepiolite ground for $10 \mathrm{~min}$ (Figure 4b), the main effect observed upon alkali treatment was the evolution of loughlinite structure. In addition, the reflections around $2 \theta=60^{\circ}$ appeared to gain on intensity in relation to the remaining peaks. The reason for the latter effect became clear after analysis of the impact the $\mathrm{NaOH}$ activation had on Sep/gr-30' and the Sep/gr-60' samples (Figure 4c,d, respectively). In both materials, features characteristic of a phase known as magnesium silicate hydrate (MSH) dominated the XRD patterns. MSH is a semi-amorphous phase of variable $\mathrm{Mg} / \mathrm{Si}$ ratio, whose structure yields broad XRD peaks around $2 \theta$ values of $20^{\circ}, 27^{\circ}, 35^{\circ}$ and $60^{\circ}$, first reported in a study of cement degradation by sea water [26]. MSH solids, which recently attracted attention as a promising, eco-friendly alternative to common, $\mathrm{CaO}$-based Portland cement, as well as catalysts and adsorbents, are readily formed in the $\mathrm{MgO}-\mathrm{SiO}_{2}-\mathrm{H}_{2} \mathrm{O}$ system, especially for the $\mathrm{Mg} / \mathrm{Si}$ ratio higher than 0.5 [27-32]. Their structure is poorly defined and appears to be related to nanocrystalline turbostratic 2:1 magnesium phyllosilicates [33]. In the most strongly ground sepiolite sample Sep/gr-60', alkali treatment also resulted in crystallization of $\mathrm{Mg}(\mathrm{OH})_{2}$, in addition to $\mathrm{MSH}$ (Figure $4 \mathrm{~d}$ ). In this material, only the small maximum at $12.7 \AA$ could be related to the remnants of the sepiolite structure, obviously heavily destroyed by the joint grinding/alkali activation. Noteworthy, in addition to the $12.7 \AA$ feature a weak broad hump evolved in this area, attributable to the layered MSH structure [33]. 

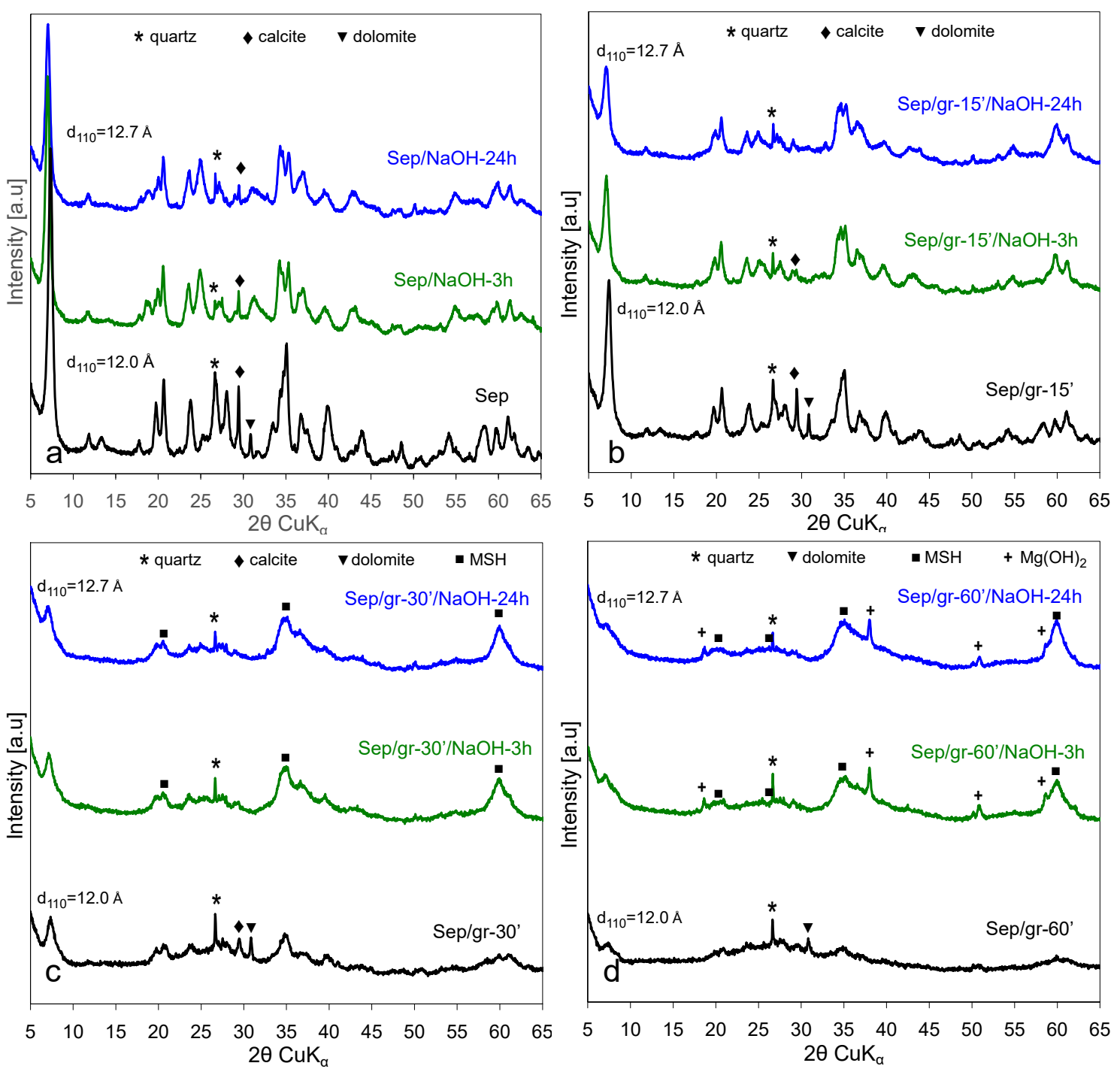

Figure 4. Effect of treatment with $\mathrm{NaOH}$ at $90{ }^{\circ} \mathrm{C}$ for 3 or $24 \mathrm{~h}$ : (a) sepiolite as-received, (b) sepiolite ground for $10 \mathrm{~min}$, (c) sepiolite ground for $30 \mathrm{~min}$, (d) sepiolite ground for $60 \mathrm{~min}$.

It should be noted that formation of $\mathrm{Mg}(\mathrm{OH})_{2}$, albeit amorphous to XRD analysis, was also observed upon alkali treatment of unground sepiolite, and resulted from formation of $\mathrm{Mg}(\mathrm{OH})_{2}$ nanoparticles within the sepiolite micropore system due to precipitation of $\mathrm{Mg}$ ions removed from the lattice upon formation of Na-sepiolite (loughlinite) [12]. Therefore, the product of wet $\mathrm{NaOH}$ activation of sepiolite has been identified as a composite of loughlinite and nano- $\mathrm{Mg}(\mathrm{OH})_{2}$. The appearance of brucite reflections in the XRD pattern of alkali-treated, most strongly ground sepiolite indicated that destruction of the parent clay lattice removed spatial constraints exerted by micropores and enabled crystallization of $\mathrm{Mg}(\mathrm{OH})_{2}$, so that the final product could be regarded as a composite of MSH and brucite, with possible traces of destroyed loughlinite structure.

\subsection{Chemical Composition}

The results of EDX analysis carried out for the investigated materials are shown in Table 1. Elemental composition of the parent sepiolite was in good agreement with the literature data for the Spanish sepiolite [34]. The only effect of grinding on the sepiolite composition was a small decrease of the amount of volatile component, pointing to a degree of sample dehydration. The relative proportions of the constituting elements remained practically constant, with the average $\mathrm{Mg} / \mathrm{Si}$ ratio equal to 0.60 . Treatment with $\mathrm{NaOH}$ solution strongly affected the composition of the recovered 
solids, the most pronounced effect being the fall of $\mathrm{SiO}_{2}$ content, in accordance with the known selective leaching of $\mathrm{Si}$ from sepiolite in the strongly basic environment [12,35]. The loss of Si during $\mathrm{NaOH}$ activation was enhanced by grinding. For selected samples the liquids remaining after alkaline activation were also subjected to chemical analysis, in order to assess the concentration of leached $\mathrm{Si}$ and $\mathrm{Mg}$, and the data are presented in Table 1. The results show that the amount of Si extracted from the sepiolite lattice grew with time of the alkali activation and was strongly enhanced by the grinding pretreatment. Thus, while ca. $16 \%$ of $\mathrm{Si}$ was removed upon $24 \mathrm{~h}$ activation at $90^{\circ} \mathrm{C}$ from the parent sepiolite, the amount of Si released from sepiolite ground for $1 \mathrm{~h}$ (Sep/gr-60'/NaOH-24 h) almost tripled. In contrast, the amount of leached $\mathrm{Mg}$ was much lower, and practically constant for all experiments. This effect, already described for alkali activation of sepiolite [12], was due to the fact that in the strongly alkaline environment any $\mathrm{Mg}^{2+}$ ions released from the sepiolite lattice upon contact with $\mathrm{NaOH}$ precipitated immediately as $\mathrm{Mg}(\mathrm{OH})_{2}$. In consequence, the concentration of $\mathrm{Mg}$ in the solution was determined by the solubility product of brucite. Accordingly, the $\mathrm{Mg} / \mathrm{Si}$ atomic ratio in the $\mathrm{NaOH}$-treated solids grew with respect to the value observed in the parent samples, both for the as-received sepiolite and for the ground materials, and could be maximized by extending the time of alkali activation and/or the grinding pretreatment. In the most strongly ground sample the degree of desilication was apparently too high to accommodate all $\mathrm{Mg}$ in the newly formed $\mathrm{MSH}$, and formation of well crystalline $\mathrm{Mg}(\mathrm{OH})_{2}$ was observed.

Table 1. EDX-determined chemical composition of selected samples (wt.\% of metal oxides and loss on ignition), $\mathrm{Mg} / \mathrm{Si}$ atomic ratio in the solids, amount of leached $\mathrm{Mg}$ and $\mathrm{Si}$ (as per cent of the initial content in the parent sample). (LOI-loss on ignition).

\begin{tabular}{cccccccccccc}
\hline Sample & $\mathbf{S i O}_{2}$ & $\mathbf{M g O}$ & $\mathbf{A l}_{\mathbf{2}} \mathbf{O}_{3}$ & $\mathbf{C a O}$ & $\mathbf{F e}_{\mathbf{2}} \mathbf{O}_{3}$ & $\mathbf{K}_{\mathbf{2}} \mathbf{O}$ & $\mathbf{N a}_{2} \mathbf{O}$ & $\mathbf{L O I}$ & $\mathbf{M g} / \mathbf{S i}$ & $\begin{array}{c}\mathbf{M g} \mathbf{L o s s} \\
{[\%]}\end{array}$ & $\begin{array}{c}\mathbf{S i} \mathbf{L o s s} \\
{[\%]}\end{array}$ \\
\hline Sep & 53.1 & 21.4 & 1.9 & 2.2 & 0.4 & 0.4 & 0.1 & 20.6 & 0.60 & - & - \\
Sep/NaOH-3 h & 49.6 & 21.9 & 2.0 & 2.2 & 0.4 & 0.4 & 3.8 & 19.7 & 0.65 & 0.3 & 9.1 \\
Sep/NaOH-24h $\mathrm{h}$ & 46.8 & 22.6 & 2.0 & 2.1 & 0.4 & 0.3 & 3.8 & 22.0 & 0.73 & 0.3 & 15.9 \\
Sep/gr-10' & 54.2 & 22.0 & 2.1 & 2.3 & 0.4 & 0.5 & 0.1 & 18.6 & 0.59 & - & - \\
Sep/gr-10'/NaOH-3 h & 46.4 & 22.4 & 2.2 & 2.2 & 0.4 & 0.5 & 3.5 & 22.5 & 0.72 & - & - \\
Sep/gr-10'/NaOH-24h h & 46.0 & 23.3 & 2.1 & 2.2 & 0.4 & 0.2 & 4.0 & 21.9 & 0.75 & 0.2 & 21.1 \\
Sep/gr-30' & 54.5 & 22.3 & 2.2 & 2.1 & 0.4 & 0.5 & 0.1 & 17.9 & 0.61 & - & - \\
Sep/gr-30'/NaOH-3 h & 46.0 & 26.1 & 2.4 & 2.6 & 0.5 & 0.3 & 2.2 & 19.9 & 0.85 & - & - \\
Sep/gr-30'/NaOH-24h h & 40.3 & 25.4 & 2.9 & 2.9 & 0.8 & 0 & 2.9 & 25.0 & 0.93 & 0.3 & 34.1 \\
Sep/gr-60' & 55.4 & 21.8 & 2.0 & 2.5 & 0.4 & 0.5 & 0.2 & 17.3 & 0.59 & - & - \\
Sep/gr-60'/NaOH-3 h & 40.5 & 27.2 & 2.3 & 2.6 & 0.4 & 0 & 1.4 & 25.6 & 1.00 & - & - \\
Sep/gr-60'/NaOH-24h h & 38.5 & 28.2 & 2.5 & 2.7 & 0.4 & 0 & 1.7 & 26.0 & 1.09 & 0.3 & 43.8 \\
\hline
\end{tabular}

An increase of Na content was observed in the alkali-treated samples, the effect being most pronounced for the as-received sepiolite and for the Sep/gr-10' sample subjected to the shortest grinding time (Table 1). In the latter samples the sepiolite lattice was either undamaged, or relatively little disturbed, and the effect could be assigned to the formation of Na-sepiolite (loughlinite), evidenced by XRD. In strongly ground Sep/gr-30' and Sep/gr-60', in which evolution of MSH phase was observed in XRD patterns, the uptake of sodium decreased, thus confirming that grinding-induced amorphization had a profound impact on the route of chemical transformation of sepiolite.

\subsection{FTIR Spectroscopy}

FTIR spectroscopy proved to be a sensitive tool in determining the effects of various treatments on the bonding within the sepiolite structure [36-44]. Figure 5 shows the evolution of FTIR spectra upon increasing time of grinding in the $4000-3000 \mathrm{~cm}^{-1}$ range, where $\mathrm{OH}$ stretching modes are observed, and in the $1800-400 \mathrm{~cm}^{-1}$ region, in which water deformation and lattice modes appear. The assignments of bands follow our previous work and the references therein [12]. 

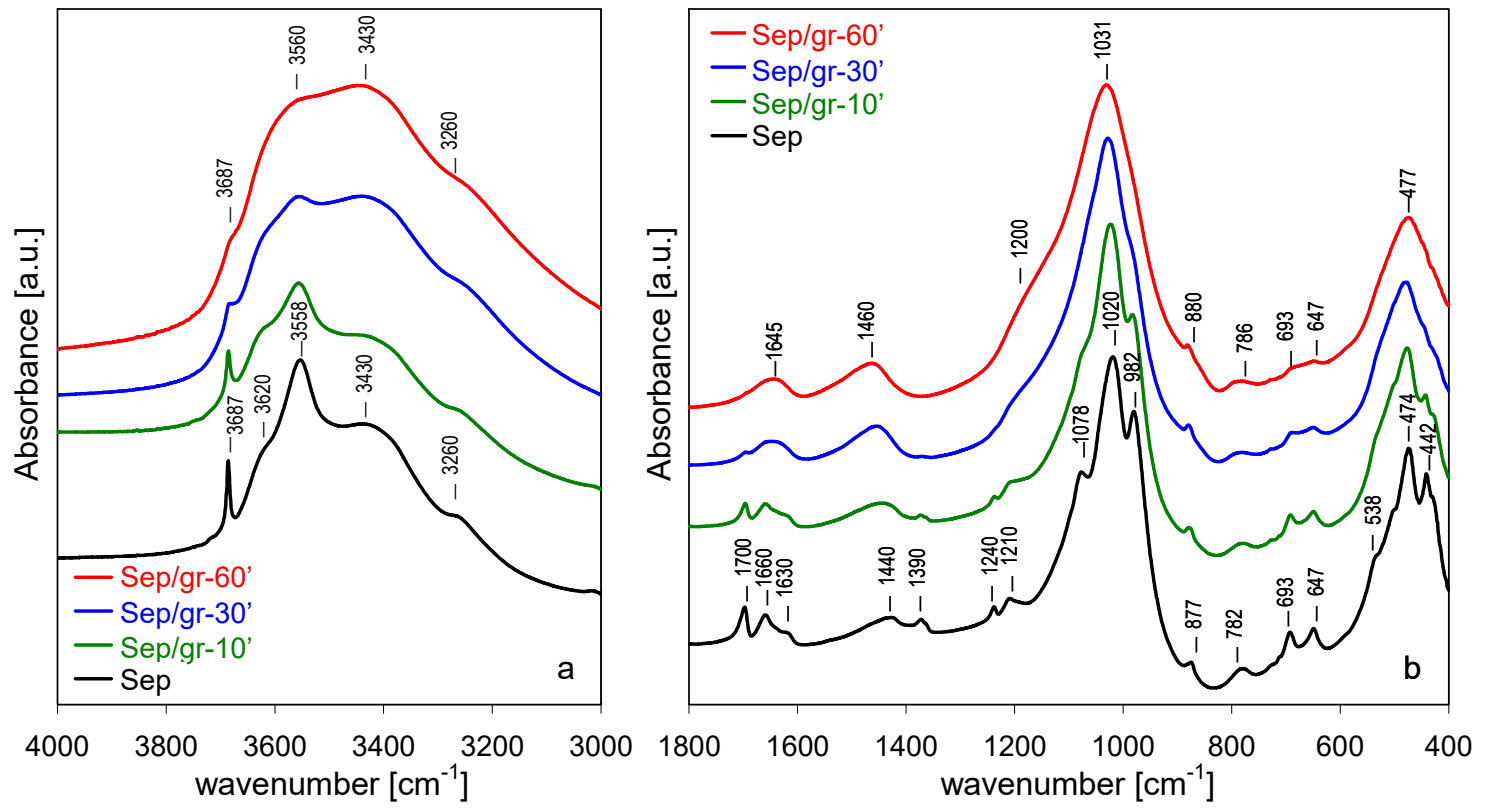

Figure 5. Evolution of FTIR spectra for sepiolite ground for different periods: (a) $3000-4000 \mathrm{~cm}^{-1}$, (b) $400-1800 \mathrm{~cm}^{-1}$.

In the 4000-3000 $\mathrm{cm}^{-1}$ range (Figure 5a) sepiolite displays a sharp band at $3687 \mathrm{~cm}^{-1}$, corresponding to $v_{\mathrm{OH}}$ stretching mode in $\mathrm{Mg}_{3} \mathrm{OH}$ units in the octahedral layer [37]. The broad bands at 3620 and $3558 \mathrm{~cm}^{-1}$ were assigned to $\mathrm{OH}$ stretching vibrations in $\mathrm{H}_{2} \mathrm{O}$ molecules coordinated to $\mathrm{Mg}$ at the ribbon edges [42], but it is possible that the former band could contain a contribution from $\mathrm{OH}$ stretches in dioctahedral defects associated with the presence of $\mathrm{Fe}$ and/or $\mathrm{Al}$ impurities cations in the octahedral layer $[40,42]$. The bands at 3430 and $3260 \mathrm{~cm}^{-1}$ were assigned to zeolitic water with, respectively, a lower and higher degree of hydrogen bonding [36,40].

In the $1800-400 \mathrm{~cm}^{-1}$ region (Figure $5 \mathrm{~b}$ ) three bands corresponding to $\mathrm{OH}$ bending mode were distinguished, with maxima around 1630, 1660, and $1700 \mathrm{~cm}^{-1}$, attributed to coordination water, and two types of zeolitic water with increasing strength of hydrogen bonding, respectively [36,37]. The bands at 1440 and $1390 \mathrm{~cm}^{-1}$ were due to carbonate impurities [45]. The strongest bands at 1020 and $982 \mathrm{~cm}^{-1}$ stemmed from Si-O in-plane stretching vibration, the $1078 \mathrm{~cm}^{-1}$ mode from out-of-plane Si-O stretches [42,44] and the $1210 \mathrm{~cm}^{-1}$ band was associated with the asymmetric stretching vibration of Si-O-Si linkages between the inverted tetrahedra at the joints of alternating ribbons [38]. The $877 \mathrm{~cm}^{-1}$ band was due to the deformation mode of carbonate impurities [46]. The $782 \mathrm{~cm}^{-1}$ band was attributed to O-Si-O and/or Si-O-Si bending vibrations [47], and the 693 and $647 \mathrm{~cm}^{-1}$ modes stemmed from translations and bends of hydroxyls in $\mathrm{Mg}_{3} \mathrm{OH}$ groupings, respectively [40,43]. The shoulder at $538 \mathrm{~cm}^{-1}$ corresponded to $\mathrm{Mg}-\mathrm{OH}$ vibration and the band at $474 \mathrm{~cm}^{-1}$ was due to the Si-O-Si bends [44]. The band at $442 \mathrm{~cm}^{-1}$ was recently attributed to the deformation mode of $\mathrm{MgO}_{6}$ octahedral units, based on its response to $\mathrm{NaOH}$ activation [12] and by analogy to the spectrum of related mineral, palygorskite [47]. The low-intensity band at $1240 \mathrm{~cm}^{-1}$ was assigned to 5 -member ring-like structural defects [12].

Grinding of sepiolite caused changes in FTIR spectra, similar to those reported previously [17]. In the range of $\mathrm{OH}$ stretching modes, the most pronounced line-shape alteration involved $\mathrm{OH}$ vibrations in structurally well-defined environments, i.e., the $3687 \mathrm{~cm}^{-1}$ band of $\mathrm{Mg}_{3} \mathrm{OH}$ groupings, and the 3620 and $3558 \mathrm{~cm}^{-1}$ bands due to $\mathrm{H}_{2} \mathrm{O}$ molecules coordinated to external $\mathrm{Mg}$ sites at the ribbon edges. The former, sharp and intense in the parent sepiolite, appeared only as a weak inflection in the most heavily ground sample. This broadening and loss of intensity is indicative of the growing disorder within the octahedral layer. The bands due to $\mathrm{OH}$ stretches in water attached to $\mathrm{Mg}$ also broadened considerably and lost intensity, while the absorption intensity in the area of broadened 
3430 and $3260 \mathrm{~cm}^{-1}$ bands became distinctly higher. The effect was most likely related to increased contribution from water hydrogen bonded to surface silanols generated during lattice disruption due to prototropy, i.e., diffusion of protons from their original siting within the clay structure to recombine with broken bonds [48]. Spectra evolved also in the $1800-400 \mathrm{~cm}^{-1}$ range. The resolved $\mathrm{OH}$ bending modes, characteristic of various types of structural water, broadened and ultimately appeared as a single envelope around $1645 \mathrm{~cm}^{-1}$. Evolution of $\mathrm{OH}$ vibrational modes upon grinding of sepiolite has been attributed to the effect known as prototropy, which caused a transfer of some protons from the bound and/or zeolitic water to grinding-induced broken bonds in the amorphized sepiolite lattice, to form weakly bound hydroxyls [17]. Grinding also affected bonds within the silicate framework. This was evidenced by a significant broadening of Si-O stretching modes at 1210, 1078,1020 and $982 \mathrm{~cm}^{-1}$, which reflected a growing structural disorder within the Si-O sublattice. Eventually, in the Sep/gr-60' sample, the bands merged into a broad, single absorption centered at $1031 \mathrm{~cm}^{-1}$. Simultaneous evolution of a broad shoulder near $1200 \mathrm{~cm}^{-1}$ showed that degradation of the silicate sheets led to the formation of a certain amount of amorphous hydrous silica phase [49]. The process was likely facilitated by the occurrence of prototropy. All other sepiolite lattice modes, both those related to the tetrahedral $\left(782,474 \mathrm{~cm}^{-1}\right)$ and to the octahedral sheets $\left(693,647\right.$, and $\left.442 \mathrm{~cm}^{-1}\right)$, were likewise significantly broadened by grinding, indicating that all associated lattice bondings were susceptible to destruction by the mechanochemical treatment. The carbonate stretching modes stemming from calcite and dolomite impurities also changed upon grinding, and yielded, eventually, a single, broad band around $1460 \mathrm{~cm}^{-1}$, the effect consistent with the structural degradation evidenced by XRD analysis.

Upon treatment with $\mathrm{NaOH}$ solution a set of changes was observed in the FTIR spectra of treated solids, albeit of different character, depending on the degree of grinding pretreatment. As previously reported [12], in the case of the as-received sepiolite, the most important effects in the $3000-4000 \mathrm{~cm}^{-1}$ range were related to $\mathrm{OH}$ stretches in species interacting directly with $\mathrm{Mg}$ sites (Figure 6a). As alkali activation progressed, the band at $3687 \mathrm{~cm}^{-1}$, associated with the $v_{\mathrm{OH}}$ stretching mode in $\mathrm{Mg}_{3} \mathrm{OH}$ entities in the octahedral layer, became increasingly broadened, while the bands related to water coordinated to $\mathrm{Mg}$ centers at the ribbon edges broadened and merged to yield a maximum at ca. $3600 \mathrm{~cm}^{-1}$. The changes reflected the fact that the nearest environment of $\mathrm{Mg}_{3} \mathrm{OH}$ units became less uniform as a result of structural damage caused by extraction of $\mathrm{Si}$ and/or removal of external $\mathrm{Mg}$ sites during alkaline activation and formation of $\mathrm{Na}$-sepiolite. Moreover, as a result of $\mathrm{NaOH}$ treatment, a shoulder of growing intensity appeared around $3710 \mathrm{~cm}^{-1}$, attributed to magnesium hydroxide nanoclusters formed within the pore system of $\mathrm{NaOH}$-activated sepiolite [12]. The positions of bands at 3260 and $3430 \mathrm{~cm}^{-1}$ corresponding to $\mathrm{OH}$ stretches in hydrogen bonded zeolitic water were not sensitive to alkaline activation, but there was an increase of their relative intensity, assigned to the effect of sodium for magnesium substitution, and to the increased contribution of $\mathrm{H}_{2} \mathrm{O}$ hydrogen bonded to surface silanols.

Analysis of $1800-400 \mathrm{~cm}^{-1}$ spectral range showed that $\mathrm{NaOH}$ treatment predominantly affected the bands related to vibrations involving Si sites, in accordance with the observed selective leaching of $\mathrm{Si}$ (Figure 6b). The increasing disorder within the silicate layers was reflected in a broadening of bands corresponding to stretching vibrations of Si-O (1210, 1078, 1020 and $982 \mathrm{~cm}^{-1}$ ) and O-Si-O and/or Si-O-Si bending modes (782 and $474 \mathrm{~cm}^{-1}$ ). In contrast, the bands involving translation and bending of hydroxyls in $\mathrm{Mg}_{3} \mathrm{OH}\left(693 \mathrm{~cm}^{-1}\right.$ and the $\left.647 \mathrm{~cm}^{-1}\right)$ and deformation mode of $\mathrm{MgO}_{6}$ units $\left(442 \mathrm{~cm}^{-1}\right)$ were only slightly affected by the alkaline treatment, indicating that except for the partial loss of $\mathrm{Mg}$ from the ribbon edges due to the exchange with sodium cations, the octahedral layer retained its identity. 

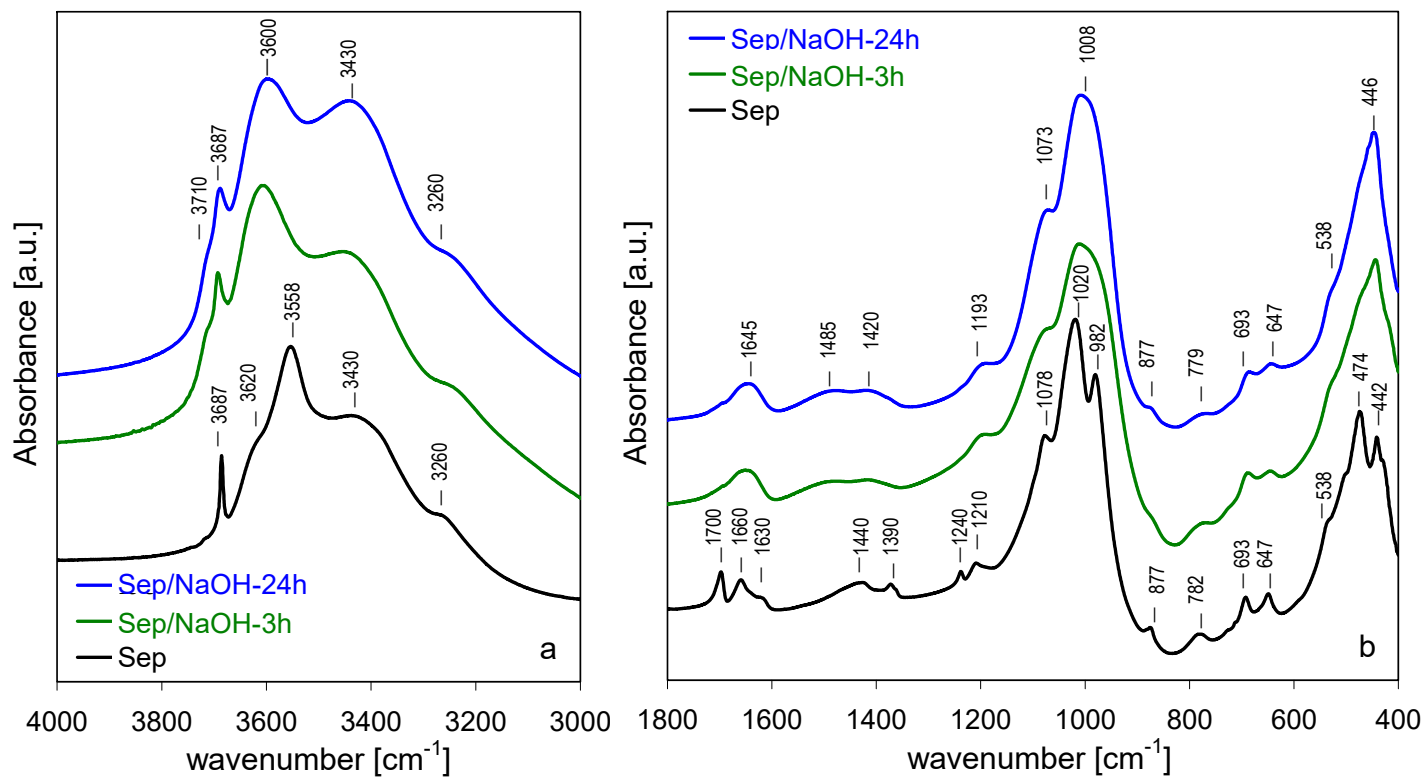

Figure 6. Evolution of FTIR spectra for sepiolite treated with $\mathrm{NaOH}$ at $90^{\circ} \mathrm{C}$, time effect: (a) $3000-4000 \mathrm{~cm}^{-1}$, (b) $400-1800 \mathrm{~cm}^{-1}$.

The effect of $\mathrm{NaOH}$ activation of the spectra of shortly ground sepiolite sample (Figure 7a,b) was quite similar to that observed for the parent sepiolite, in line with XRD data pointing to relatively small structural differences between Sep and Sep/gr-10', and between their alkali-treated derivatives. However, a small but meaningful difference could be found in the $\mathrm{OH}$ stretching range, where neither in Sep/gr-10'/NaOH-3 h nor in Sep/gr- $10^{\prime} / \mathrm{NaOH}-24 \mathrm{~h}$ a shoulder around $3710 \mathrm{~cm}^{-1}$ was observed, pointing to the absence of a significant amount of intraporous nanocrystalline $\mathrm{Mg}(\mathrm{OH})_{2}$ deposit.
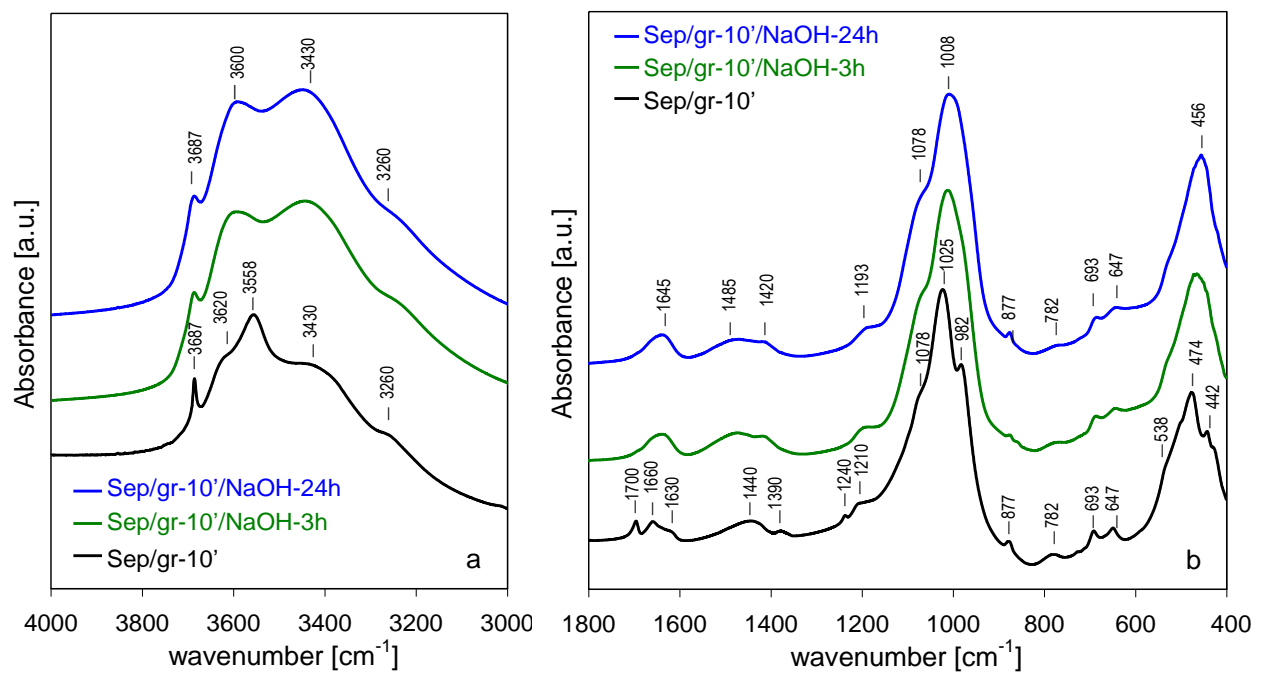

Figure 7. Evolution of FTIR spectra for sepiolite ground for $10 \mathrm{~min}$ and treated with $\mathrm{NaOH}$ at $90{ }^{\circ} \mathrm{C}$, time effect: (a) $3000-4000 \mathrm{~cm}^{-1}$, (b) $400-1800 \mathrm{~cm}^{-1}$.

FTIR spectra of $\mathrm{NaOH}$-treated Sep/gr-30' and Sep/gr-60' samples showed that the heavily ground materials responded differently to the alkali attack (Figures 8 and 9). Although the spectra of starting materials were significantly broadened, several meaningful changes could be observed upon $\mathrm{NaOH}$ treatment. In the $3000-4000 \mathrm{~cm}^{-1}$ range the most striking effect was the increase of $3687 \mathrm{~cm}^{-1}$ band of $v_{\mathrm{OH}}$ stretching mode in $\mathrm{Mg}_{3} \mathrm{OH}$ groupings, indicating that during alkali treatment of the amorphized material a reconstruction of the Mg-based sheet occurs (Figures 8a and 9a). In addition, in the 
Sep/gr- $60^{\prime} / \mathrm{NaOH}-24 \mathrm{~h}$ sample, a sharp band at $3695 \mathrm{~cm}^{-1}$, related to $\mathrm{OH}$ stretches in crystalline $\mathrm{Mg}(\mathrm{OH})_{2}$ appeared next to $3687 \mathrm{~cm}^{-1}$ one, in agreement with the XRD evidence pointing to the evolution of this phase in the most strongly ground material. Changes visible in the $400-1800 \mathrm{~cm}^{-1}$ range were consistent with the formation of layer-structured magnesium silicate hydrate phase, evidenced by XRD (Figures $8 \mathbf{b}$ and $9 \mathrm{~b}$ ). Thus, the most intense Si-O stretching maximum shifted to $1014 \mathrm{~cm}^{-1}$, accompanied by the appearance of broad shoulders around $880 \mathrm{~cm}^{-1}$ and $680 \mathrm{~cm}^{-1}$, due to $\mathrm{Si}-\mathrm{OH}$ vibrations and to libration modes of $\mathrm{Mg}_{3} \mathrm{OH}$ units, respectively, as expected for the evolution of MSH [50-52].
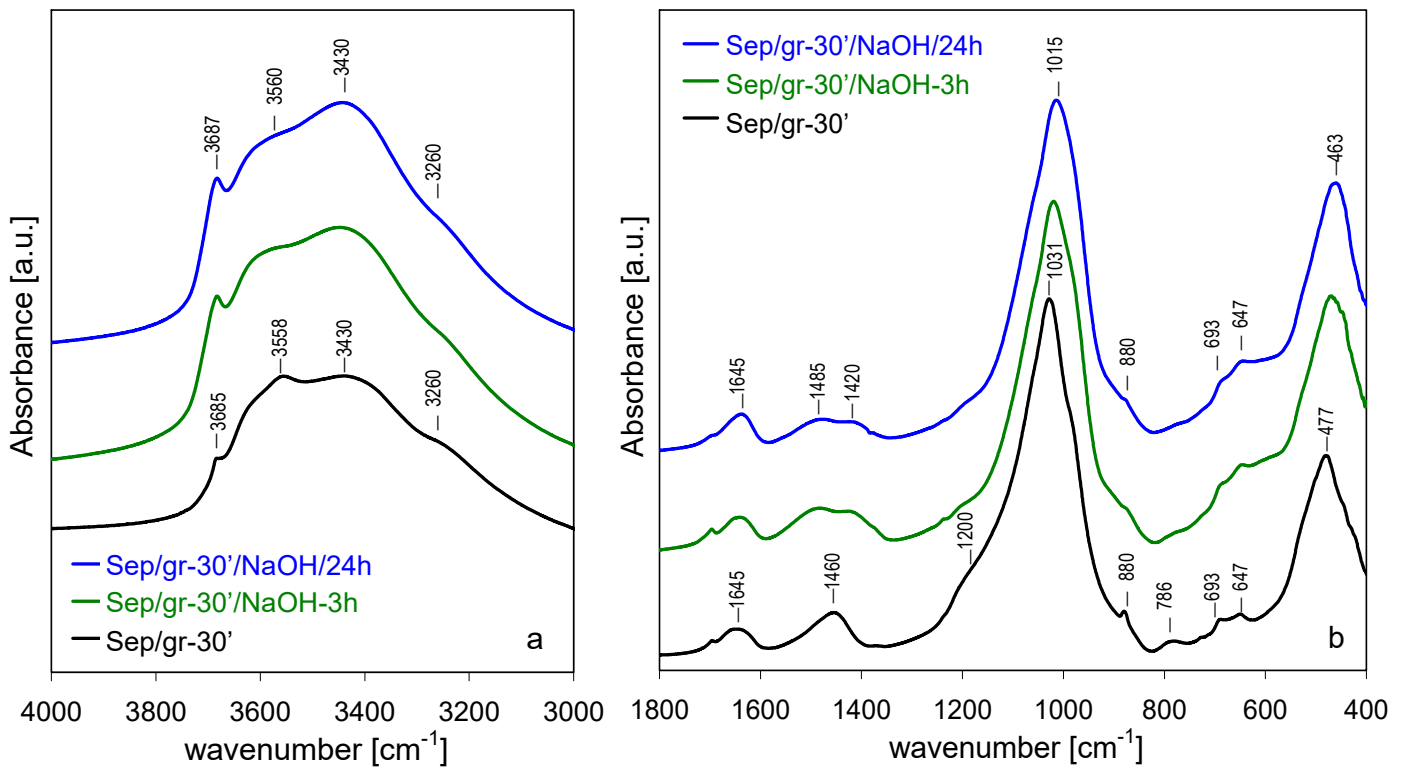

Figure 8. Evolution of FTIR spectra for sepiolite ground for $30 \mathrm{~min}$ and treated with $\mathrm{NaOH}$ at $90{ }^{\circ} \mathrm{C}$, time effect: (a) $3000-4000 \mathrm{~cm}^{-1}$, (b) $400-1800 \mathrm{~cm}^{-1}$.
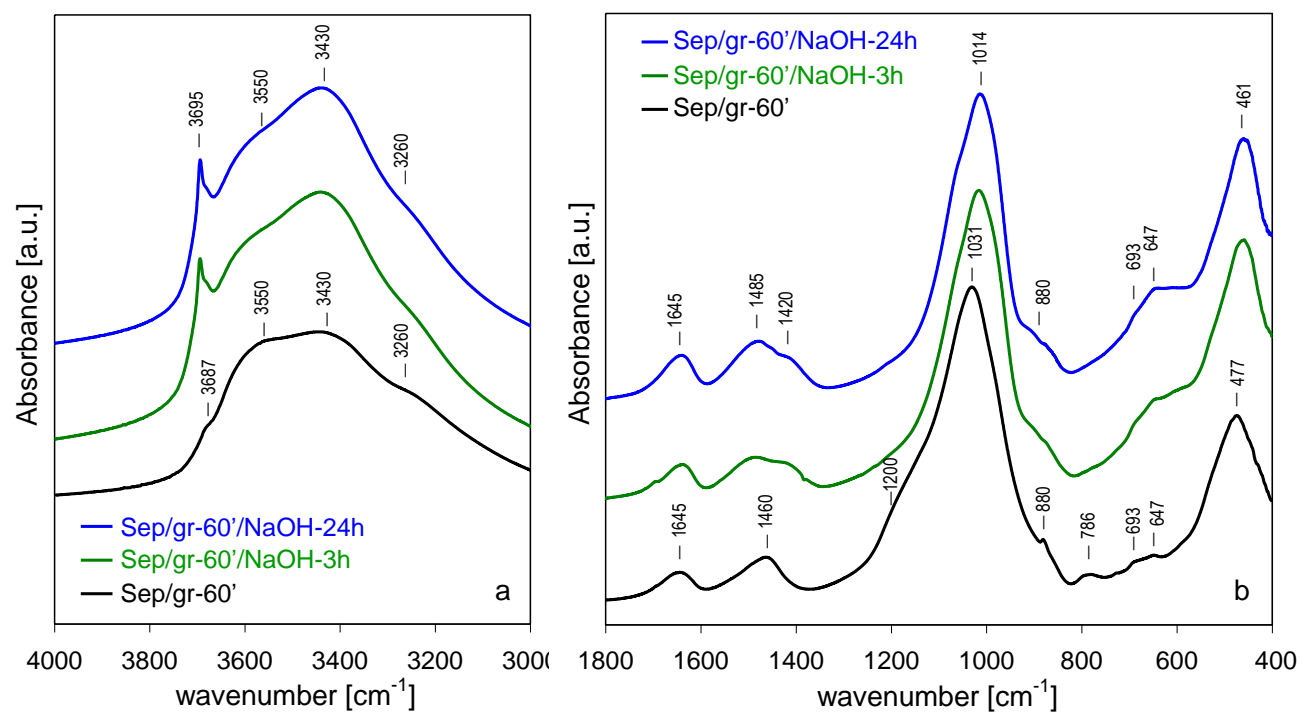

Figure 9. Evolution of FTIR spectra for sepiolite ground for $60 \mathrm{~min}$ and treated with $\mathrm{NaOH}$ at $90{ }^{\circ} \mathrm{C}$, time effect: (a) $3000-4000 \mathrm{~cm}^{-1}$, (b) $400-1800 \mathrm{~cm}^{-1}$.

Noteworthy: the shoulder around $1200 \mathrm{~cm}^{-1}$, evidencing the presence of amorphous hydrous silica in the ground samples, disappeared after alkali treatment. This observation, combined with the fact that in the shortly ground sample there was no evidence of a shoulder at $3710 \mathrm{~cm}^{-1}$ characteristic of intraporous nanocrystalline $\mathrm{Mg}(\mathrm{OH})_{2}$, suggested that both phases were consumed in the process of MSH 
formation, as described by Walling et al. [51]. Only in the heavily ground sample, where Si-leaching resulted in $\mathrm{Mg} / \mathrm{Si}$ ratio $\geq 1$, the excess $\mathrm{Mg}$ crystallized as a separate, spatially unrestricted $\mathrm{Mg}(\mathrm{OH})_{2}$ phase, responsible for the appearance of the sharp $3695 \mathrm{~cm}^{-1}$ band.

\section{5. ${ }^{29}$ Si MAS NMR Spectroscopy}

${ }^{29} \mathrm{Si}$ MAS NMR spectroscopy enables insight into the structural details of silicate frameworks. In particular, the position of ${ }^{29} \mathrm{Si}$ signal is sensitive to the degree of silicate lattice polymerization. In general, the sites with various connectivity are described as $Q^{n}$, where $Q$ denotes the Si center bonded to four oxygens and the superscript represents the number of other $S i$ atoms bonded by oxygen bridges to $\mathrm{Q}$ site [53]. Thus, $\mathrm{Q}^{0}$ corresponds to monosilicates, $\mathrm{Q}^{1}$ to disilicates and chain end groups, $\mathrm{Q}^{2}$ to internal groups in chains, $Q_{3}$ to chain branching sites and $Q^{4}$ to the three-dimensional cross-linked framework. In the case of untreated sepiolite, whose structure is characterized by three crystallographically different $\mathrm{Q}^{3}$ Si positions (edge, near-edge and center of the ribbon, Figure 1), the ${ }^{29} \mathrm{Si}$ MAS NMR spectrum consisted of three well-resolved resonances at $-92.0,-94.5$ and $-98.0 \mathrm{ppm}$ (Figure 10a), stemming from $\mathrm{Si}$ centers located in the near-edge, center and edge positions, respectively [54-56]. A weak resonance at $-85.9 \mathrm{ppm}$ was attributed to surface $\mathrm{Q}^{2}$ silanol groups [53]. Details of the spectra deconvolution are given in Table 2.
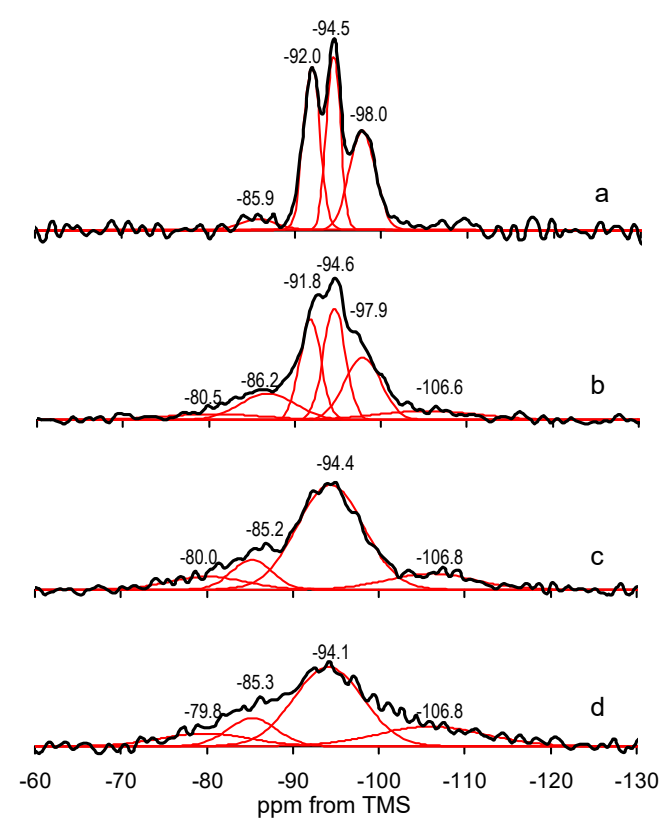
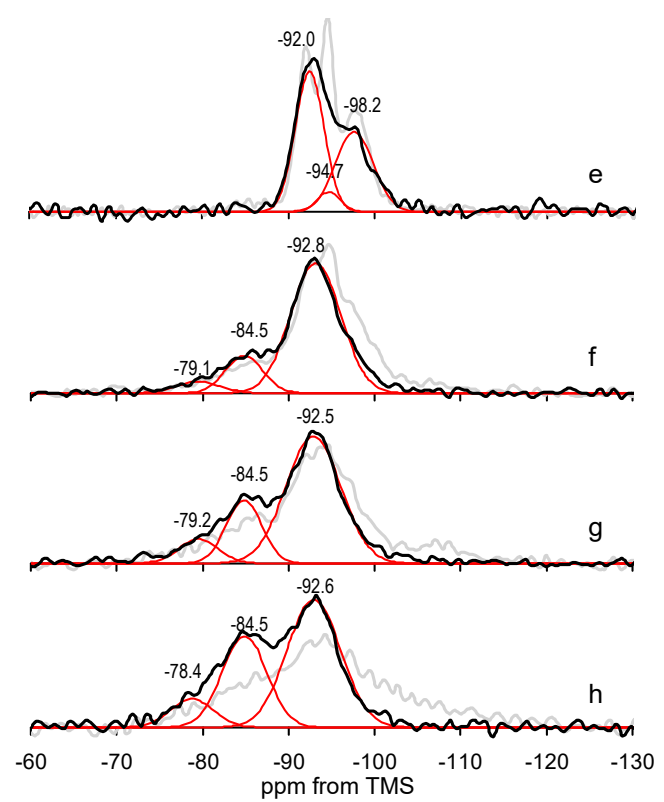

Figure 10. Evolution of ${ }^{29}$ Si MAS NMR of sepiolite samples upon grinding: (a) Sep, (b) Sep/gr-10', (c) Sep/gr-30', (d) Sep/gr-60' and after treatment with $\mathrm{NaOH}$ at $90^{\circ} \mathrm{C}$ for $24 \mathrm{~h}:$ (e) Sep/NaOH-24 h, (f) Sep/gr-10'/NaOH-24 h, (g) Sep/gr-30'/NaOH-24 h, (h) Sep/gr-60'/NaOH-24 h. Red lines represent deconvoluted spectrum components. For comparison, the spectra of samples before alkali treatment are shown in grey.

In the spectrum of Sep/gr-10' all three $\mathrm{Q}^{3}$ components were still visible, but their broadening reflected the occurrence of grinding-induced lattice disorder (Figure 10f). Partial destruction of the lattice was accompanied by the appearance of new resonances, at -80.0 and $-106.6 \mathrm{ppm}$, attributed to $\mathrm{Q}^{1}$ and $\mathrm{Q}^{4}$ silicon environments, respectively. Emergence of $\mathrm{Q}^{1}$ and increase of $\mathrm{Q}^{2}$ indicated that milling caused a degree of depolymerization of the silicate framework, while the growth of $\mathrm{Q}^{4}$ evidenced formation of amorphous silica matter. ${ }^{29}$ Si MAS NMR spectra of Sep/gr-30' and Sep/gr-60' reflected growing degradation of the sepiolite lattice (Figure $10 \mathrm{~g}, \mathrm{~h}$ ). The initial $\mathrm{Q}^{3}$ resonances were no longer resolved and appeared as one broad signal around -94 ppm, and the share of $Q^{1}, Q^{2}$ and $Q^{4}$ 
absorptions increased, in accordance with the XRD data evidencing almost complete disappearance of reflections characteristic of ordered sepiolite lattice.

Table 2. Parameters of ${ }^{29}$ Si MAS NMR spectra components obtained from deconvolution.

\begin{tabular}{|c|c|c|c|c|c|}
\hline Sample & $\begin{array}{c}{ }^{29} \text { Si MAS NMR } \\
\text { Parameter }\end{array}$ & $Q^{1}$ & $Q^{2}$ & $\mathrm{Q}^{3}$ & $\mathrm{Q}^{4}$ \\
\hline \multirow{3}{*}{ Sep } & center (ppm) & - & -85.9 & $-92.0,-94.5,-98.0$ & - \\
\hline & FWHM (ppm) & - & 4.9 & $2.2,1.9,3.5$ & - \\
\hline & intensity $(\%)$ & - & 4 & $34,30,32$ & - \\
\hline \multirow{3}{*}{ Sep/NaOH-24 h } & center (ppm) & - & - & $-92.5,-94.7,-97.6$ & - \\
\hline & FWHM (ppm) & - & - & $3.9,3.1,5.1$ & - \\
\hline & intensity $(\%)$ & - & - & $54,6,40$ & - \\
\hline \multirow{3}{*}{ Sep/gr-10' } & center (ppm) & -80.5 & -86.2 & $-91.8,-94.6,-97.9$ & -106.6 \\
\hline & FWHM (ppm) & 10.3 & 5.7 & $3.2,3.1,5.1$ & 11.2 \\
\hline & intensity (\%) & 7 & 13 & $23,26,22$ & 9 \\
\hline \multirow{3}{*}{ Sep/gr-10'/NaOH-24 h } & center (ppm) & -79.1 & -84.5 & -92.8 & - \\
\hline & FWHM (ppm) & 5.9 & 5.1 & 6.9 & - \\
\hline & intensity $(\%)$ & 5 & 17 & 78 & - \\
\hline \multirow{3}{*}{ Sep/gr-30' } & center (ppm) & -80.0 & -85.2 & -94.4 & -106.8 \\
\hline & FWHM (ppm) & 10.1 & 5.5 & 9.1 & 11.8 \\
\hline & intensity (\%) & 9 & 11 & 67 & 13 \\
\hline \multirow{3}{*}{ Sep/gr-30'/NaOH-24 h } & center (ppm) & -79.2 & -84.5 & -92.5 & - \\
\hline & FWHM (ppm) & 5.4 & 4.9 & 7.6 & - \\
\hline & intensity (\%) & 9 & 22 & 69 & - \\
\hline \multirow{3}{*}{ Sep/gr-60' } & center (ppm) & -79.8 & -85.3 & -94.1 & -106.8 \\
\hline & FWHM (ppm) & 12.0 & 6.7 & 9.5 & 14.5 \\
\hline & intensity (\%) & 11 & 13 & 55 & 21 \\
\hline \multirow{3}{*}{ Sep/gr-60'/NaOH-24 h } & center (ppm) & -78.4 & -84.5 & -92.6 & - \\
\hline & FWHM (ppm) & 5.9 & 6.1 & 7.4 & - \\
\hline & intensity (\%) & 10 & 34 & 56 & - \\
\hline
\end{tabular}

The effect of alkali activation depended critically on the mineral pretreatment (Figure 10e-h). In accordance with previous findings [12], in the case of parent sepiolite, there was no visible shift of the overall resonance position, but a significant decrease of the $-94.5 \mathrm{ppm}$ component, associated with Si sites at the center of structural ribbons, was observed (Figure 10e). The effect indicated that in the untreated sepiolite $\mathrm{Si}$ is preferentially leached from the middle of the tetrahedral sheets.

The response of ground sepiolite to $\mathrm{NaOH}$ activation was different. In the shortly ground sample, in addition to the decrease of the -94.5 ppm component, also the -98.2 ppm resonance, stemming from Si linking the neighboring ribbons, diminished. This suggests that the initial damage to the structure caused by milling involved breaking of the ribbon-ribbon linkages, rendering the Si centers in broken bonds more susceptible to alkali activation. The alkali treatment removed the traces of amorphous silica present in the Sep/gr-10' sample, as evidenced by the disappearance of -106.6 ppm component, and enhanced the share of depolymerized species responsible for $\mathrm{Q}^{1}$ and $\mathrm{Q}^{2}$ resonances at -79.1 and $-84.5 \mathrm{ppm}$. Changes observed in the spectra of Sep/gr-30' and Sep/gr-60' were of similar character, i.e., the broad $\mathrm{Q}^{3}$ resonance shifted upfield to ca. -92.5 , pointing to the loss of $\mathrm{Si}$ from the center and edge positions in the remnants of sepiolite framework, the $\mathrm{Q}^{4}$ component disappeared indicating dissolution of the amorphous silica, and the contribution of the $\mathrm{Q}^{1}$ and $\mathrm{Q}^{2}$ resonances increased. The overall line-shape of Sep/gr-30'/NaOH-24 h and Sep/gr-60'/NaOH-24 h spectra, as well as positions and relative intensities of $\mathrm{Q}^{1}, \mathrm{Q}^{2}$ and $\mathrm{Q}^{3}$ components resembled those of $\mathrm{MSH}$ gels obtained from the $\mathrm{Mg}(\mathrm{OH})_{2}-\mathrm{SiO}_{2}-\mathrm{H}_{2} \mathrm{O}$ mixtures with $\mathrm{Mg} / \mathrm{Si}=1$ [51]. The result was consistent with the XRD data pointing to formation of $\mathrm{MSH}$. As previously reported, the $\mathrm{Q}^{1}$ and $\mathrm{Q}^{2}$ sites in $\mathrm{MSH}$ correspond to 
silanol species of $\mathrm{Si}-\mathrm{O}-\mathrm{Si}^{*}-\mathrm{OH}$ and $(\mathrm{Si}-\mathrm{O})_{2}-\mathrm{Si}^{*}-\mathrm{OH}$ sites, respectively $[27,30]$, which agrees with detection of silanol bands in FTIR spectra of these samples.

In summary, ${ }^{29} \mathrm{Si}$ MAS NMR analysis revealed a major difference between the as-received and the ground sepiolite with respect to alkali treatment. While $\mathrm{NaOH}$ activation of Sep sample led to the preferential leaching of Si located centrally in the structural ribbons, in ground samples a facile loss of Si from edge positions was also observed, suggesting that ribbon-ribbon linkages were particularly prone to milling-induced structural damage. Moreover, the spectra of heavily ground, $\mathrm{NaOH}$-treated samples confirmed transformation of the solids into layered MSH materials.

\subsection{Textural Properties and Surface Basicity in Relation to Catalysis and Sorption}

Our previous report showed that wet alkali activation of sepiolite strongly influenced its textural properties and surface basicity [12]. In particular, the gradual transformation of sepiolite into partially desilicated loughlinite, accompanied by intraporous formation of magnesium hydroxide nanoparticles, resulted, on one hand, in the increase of surface basicity, but on the other, caused a blocking of micropores and a fall of specific surface area. Both phenomena affected the outcome of catalytic (acetone self-condensation, cyclohexanone oxidation) and sorption $\left(\mathrm{CO}_{2}\right)$ experiments.

Textural characteristics data for materials investigated in the present work, obtained from the $\mathrm{N}_{2}$ adsorption/desorption isotherms, are summarized in Table 3. Grinding brought about a decrease of the specific surface area and q collapse of pore volume of sepiolite, the more pronounced, the longer the treatment (Sep, Sep/gr-10', Sep/gr-30', Sep/gr-60'). In general, particle diminution is expected to increase the specific surface area, but in the case of porous materials, such as sepiolite, the internal pore network may be destroyed and/or blocked by the amorphous phase produced during treatment, leading to the fall of textural parameters [17-21]. In addition, in heavily ground samples decrease of the specific surface may be due to the cold-welding effect [24], responsible for the formation of agglomerates observed in SEM study. After the most intense milling, the specific surface area and microporosity of Sep/gr-60'decreased by an order of magnitude, and the total pore volume became ca. $5 \times$ lower in comparison with the as-received Sep sample.

Table 3. Textural parameters from $\mathrm{N}_{2}$ adsorption/desorption isotherms at $-196{ }^{\circ} \mathrm{C}\left(\mathrm{S}_{\mathrm{BET}}, \mathrm{V}_{\text {tot }}, \mathrm{S}_{\text {micro }}\right.$, $\left.\mathrm{V}_{\text {micro, }}, \mathrm{D}_{\mathrm{av}}\right)$.

\begin{tabular}{|c|c|c|c|c|c|}
\hline Sample & $\begin{array}{c}\mathrm{S}_{\mathrm{BET}} \\
{\left[\mathrm{m}^{2} \mathrm{~g}^{-1}\right]}\end{array}$ & $\begin{array}{c}V_{\text {tot }} \\
{\left[\mathrm{cm}^{3} \mathrm{~g}^{-1}\right]}\end{array}$ & $\begin{array}{c}S_{\text {micro }} \\
{\left[\mathrm{m}^{2} \mathrm{~g}^{-1}\right]}\end{array}$ & $\begin{array}{c}V_{\text {micro }} \\
{\left[\mathrm{cm}^{3} \mathrm{~g}^{-1}\right]}\end{array}$ & $\begin{array}{l}\mathrm{D}_{\mathrm{av}} \\
{[\AA \AA]}\end{array}$ \\
\hline Sep & 299 & 0.44 & 140 & 0.059 & 59 \\
\hline Sep/NaOH-3 h & 108 & 0.35 & 12 & 0.005 & 131 \\
\hline Sep/NaOH-24 h & 119 & 0.37 & 20 & 0.009 & 124 \\
\hline Sep/gr-10' & 182 & 0.37 & 85 & 0.052 & 82 \\
\hline Sep/gr- $10^{\prime} / \mathrm{NaOH}-3 \mathrm{~h}$ & 228 & 0.41 & 67 & 0.031 & 73 \\
\hline Sep/gr-10'/NaOH-24 h & 223 & 0.39 & 54 & 0.025 & 69 \\
\hline Sep/gr-30' & 70 & 0.15 & 30 & 0.020 & 88 \\
\hline Sep/gr-30'/NaOH-3 h & 266 & 0.30 & 63 & 0.030 & 45 \\
\hline Sep/gr-30'/NaOH-24 h & 320 & 0.31 & 91 & 0.041 & 39 \\
\hline Sep/gr-60' & 31 & 0.09 & 10 & 0.008 & 115 \\
\hline Sep/gr-60'/NaOH-3 h & 304 & 0.29 & 83 & 0.039 & 38 \\
\hline Sep/gr-60'/NaOH-24 h & 328 & 0.34 & 63 & 0.030 & 41 \\
\hline
\end{tabular}

Analysis of textural data for $\mathrm{NaOH}$-activated samples showed that impact of alkali treatment on the texture of the as-received sepiolite differed significantly from the effect it had on ground samples. Thus, in the case of unground mineral, a significant loss of the specific surface area occurred, mainly on the account of a dramatic reduction of sample microporosity, as both the micropore surface and the micropore volume fell by an order of magnitude (samples Sep, Sep/NaOH-3 h, Sep/NaOH-24 h). Elimination of micropores was paralleled by an increase of the average pore diameter. As reported previously [12], the effect was due to blocking of the micropore system by $\mathrm{Mg}(\mathrm{OH})_{2}$ nanoparticles 
formed as a result of instantaneous precipitation of $\mathrm{Mg}$ ions released upon formation of Na-sepiolite. A slight increase of the specific surface area and pore volume observed in the Sep/NaOH-24 h sample subjected to the most severe treatment possibly reflected the progressing corrosion of tetrahedral silica layers due to the abrasive action of alkali solution.

In contrast, in the case of ground sepiolite treated with $\mathrm{NaOH}$, the specific surface area and porosity increased significantly. Comparison of textural data obtained for the shortly ground Sep/gr-10' sample, with those of the parent sepiolite, showed that behavior of both materials in the alkaline environment was very different, despite close structural resemblance visible in XRD. In particular, the effect of almost complete blockage of microporosity in $\mathrm{NaOH}$-treated Sep, caused by precipitation of $\mathrm{Mg}(\mathrm{OH})_{2}$ nanoparticles, was absent in alkali activates Sep/gr-10', for which microporosity decreased to a much lesser degree. The phenomenon was consistent with results of FTIR data which did not detect the presence of nanocrystalline $\mathrm{Mg}(\mathrm{OH})_{2}$ deposit in $\mathrm{NaOH}$-treated Sep/gr-10' samples (lack of $3710 \mathrm{~cm}^{-1}$ shoulder in Figure 7a). Simultaneous disappearance of grinding-generated amorphous silica resonance in ${ }^{29} \mathrm{Si}$ MAS NMR spectrum (Figure 11b) suggested that both phases were used up for the nucleation of quasi amorphous MSH [51]. Enhancement of textural parameters was particularly spectacular for samples subjected to stronger grinding pretreatment (Sep/gr-30', Sep/gr-60'), in which S exceeding $300 \mathrm{~m}^{2} / \mathrm{g}$ were observed. The effect was accompanied by an increase of microporosity and a related decrease of the average pore size. In view of the XRD data one may infer that the enhancement of textural properties was related to further build-up of MSH phase, known to display a high specific surface area and micro/mesoporous character [57].

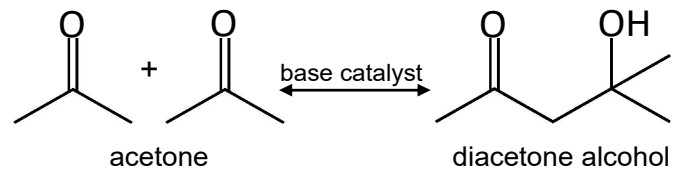

a<smiles>O=C1CCC(O)CC1</smiles>
cyclohexanone

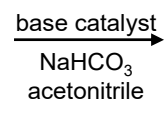$$
\text { b }
$$

Figure 11. (a) Aldol self-condensation of acetone, (b) Bayer-Villiger oxidation of cyclohexanone to $\varepsilon$-caprolactone with $\mathrm{H}_{2} \mathrm{O}_{2}$ as an oxidant.

In order to assess the total surface basicity of the investigated materials, the samples were subjected to titration with benzoic acid [58], and the data on the amount of acid probe required for surface neutralization, are presented in Table 4, both per unit mass and, in view of varying specific surface area, per unit surface. Short grinding caused a slight increase in basicity, attributed to uncovering of $\mathrm{Mg}$ sites at (110) surfaces exposed by breaking of sepiolite fibers perpendicular to lath axis (SEM image in Figure 2c). Further grinding led to lowering of basicity, when expressed per gram of the sample, but, due to the strong decrease of the specific surface area, the areal basicity steadily increased, in line with progressing fractioning of sepiolite fibers. 
Table 4. Total basicity from benzoic acid titration, yield of DAA obtained in self-condensation of acetone, yield of $\varepsilon$-caprolactone in Baeyer-Villiger oxidation of cyclohexanone, and amount of sorbed $\mathrm{CO}_{2}$. Standard error of the mean value in parentheses.

\begin{tabular}{ccccc}
\hline Sample & $\begin{array}{c}\text { Basicity } \\
{\left[\boldsymbol{\mu m o l g}^{-1}\right] /} \\
{\left[\mu \text { molm }^{-2}\right]}\end{array}$ & $\begin{array}{c}\text { DAA } \\
\text { Yield } \\
{\left[\mathbf{m m o l g}^{-1}\right]}\end{array}$ & $\begin{array}{c}\varepsilon \text {-Caprolactone } \\
\text { Yield } \\
{\left[\mathbf{m m o l g}^{-1}\right]}\end{array}$ & $\begin{array}{c}\mathbf{C O}_{2} \\
\text { Sorption } \\
{\left[\mathbf{m m o l g}^{-1}\right]}\end{array}$ \\
\hline Sep & $214 \pm 11 / 0.7$ & $0.44 \pm 0.01$ & $21.0 \pm 0.6$ & $1.5 \pm 0.02$ \\
Sep/NaOH-3 h & $1039 \pm 16 / 9.6$ & $8.64 \pm 0.03$ & $36.1 \pm 1.0$ & - \\
Sep/NaOH-24 h & $1090 \pm 22 / 9.2$ & $9.02 \pm 0.03$ & $36.9 \pm 0.7$ & 1.2 \\
Sep/gr-10' & $265 \pm 8 / 1.5$ & $2.32 \pm 0.01$ & $17.2 \pm 0.8$ & 1.1 \\
Sep/gr-10'/NaOH-3 h & $833 \pm 26 / 3.7$ & $12.21 \pm 0.03$ & $25.5 \pm 0.7$ & - \\
Sep/gr-10'/NaOH-24 h & $790 \pm 3 / 3.5$ & $14.37 \pm 0.07$ & $31.9 \pm 0.6$ & 1.3 \\
Sep/gr-30' & $167 \pm 6 / 2.3$ & $0.80 \pm 0.01$ & $16.8 \pm 0.7$ & 0.9 \\
Sep/gr-30'/NaOH-3 h & $983 \pm 33 / 3.7$ & $16.83 \pm 0.05$ & $23.1 \pm 0.6$ & - \\
Sep/gr-30'/NaOH-24 h & $1133 \pm 29 / 3.5$ & $20.62 \pm 0.03$ & $29.0 \pm 0.9$ & 1.9 \\
Sep/gr-60' & $80 \pm 4 / 2.9$ & $0.53 \pm 0.01$ & $15.7 \pm 1.0$ & 0.7 \\
Sep/gr-60'/NaOH-3 h & $986 \pm 33 / 3.2$ & $18.11 \pm 0.04$ & $25.2 \pm 0.6$ & - \\
Sep/gr-60'/NaOH-24 h & $1185 \pm 45 / 3.6$ & $17.59 \pm 0.05$ & $25.6 \pm 0.9$ & 1.8 \\
\hline
\end{tabular}

In all cases treatment with $\mathrm{NaOH}$ led to enhancement of basicity. The strong increase of basicity in Sep/NaOH-3 $\mathrm{h}$ and Sep/NaOH-24 h with respect to the Sep sample was attributed to the formation of nanocrystalline $\mathrm{Mg}(\mathrm{OH})_{2}$ precipitate [12]. In the case of ground samples, the increase of areal basicity was less pronounced, which suggested a different nature of basic sites. Indeed, nanocrystalline $\mathrm{Mg}(\mathrm{OH})_{2}$ was undetectable in these samples, and the weaker basicity had to be related to the newly generated MSH phase and/or loughlinite present in Sep/gr-10'/NaOH-3 $\mathrm{h}$ and Sep/gr- $10^{\prime} / \mathrm{NaOH}-24 \mathrm{~h}$ samples. The appearance of well crystalline $\mathrm{Mg}(\mathrm{OH})_{2}$ in $\mathrm{NaOH}$-treated Sep/gr-60' samples did not cause a significant change in the observed basicity trend.

Base catalyzed reactions, i.e., liquid phase aldol self-condensation of acetone and liquid phase Baeyer-Villiger oxidation of cyclohexanone to $\varepsilon$-caprolactone were carried out in order to check how the modification of texture and surface basicity impacts the catalytic properties of the investigated samples.

Aldol condensation consists in reaction of two molecules with carbonyl groups to give hydroxylketones or unsaturated ketones and plays an important role in biomass feedstock transformation $[59,60]$. Aldol self-condensation of acetone yields diacetone alcohol (DAA) as the primary product (Figure 11a). The catalysts obtained in the present work were used as-received, without any thermal pretreatment. DAA was the only product of the acetone self-condensation reaction. The data in Table 4 show that both for the as-received and for the ground sepiolite samples the yield of DAA increased after alkali activation. Surprisingly, the enhancement of self-condensation activity was more pronounced on catalysts derived from ground samples, despite their lower areal basicity. Effects of this type were observed in other catalytic systems, when the catalyst surface displayed bifunctional, acid-base properties, because aldol condensations may also be catalyzed by acid sites [61-63]. In particular, weakly acidic silanol groups were found particularly suitable for cooperatively catalyzing the aldol condensation [63]. The presence of silanols in $\mathrm{NaOH}$-treated, ground sepiolite catalysts was evidenced by FTIR and ${ }^{29} \mathrm{Si} \mathrm{MAS} \mathrm{NMR} \mathrm{data.} \mathrm{In} \mathrm{view} \mathrm{of} \mathrm{this,} \mathrm{it} \mathrm{is}$ proposed that the superior aldol condensation activity of catalysts derived from ground samples was due to the formation of MSH phase, enabling cooperative action of Mg-related basic sites and silanols.

A different trend in catalytic activity was observed in the other test reaction, the Baeyer-Villiger oxidation of cyclohexanone to $\varepsilon$-caprolactone, the monomer used for manufacturing of biodegradable polymers [64]. Currently employed industrial processes are based on the stoichiometric reaction and use explosive organic peroxides, thereby generating copious amount of acid waste. Catalytic reaction with use of $\mathrm{H}_{2} \mathrm{O}_{2}$ as an oxidant represents an eco-friendly alternative [65] (Figure 11b). Addition of bicarbonate has a neutralizing effect on the reaction medium acidified by the presence of $\mathrm{H}_{2} \mathrm{O}_{2}$, which is beneficial for the basic catalyst, and provides an additional route of hydrogen peroxide 
activation [66], thus enhancing the reaction yield [23]. The reaction proceeded with ca. $70 \%$ selectivity over ground sepiolite samples, and with $\geq 90 \%$ selectivity over all remaining catalysts. According to the GC-MS analysis of the reaction mixture the nonselective products included cyclohexanone oxime and nitrocyclohexane, as well as several unidentified substances with much longer retention times, possibly corresponding to some polymerized products. The appearance of nitrogen-containing products pointed to the participation of the acetonitrile solvent in the nonselective reaction routes. The data on the $\varepsilon$-caprolactone yield gathered in Table 4 show that, in general, ground catalysts and their $\mathrm{NaOH}$-treated derivatives performed poorer than the as-received sepiolite and the catalysts obtained by its alkali activation. Although in each case alkali treatment brought about an increase in the $\varepsilon$-caprolactone yield, the effect was most pronounced for unground sepiolite, and gradually diminished for the catalysts obtained from milled samples. The results indicated that the MSH phase, developed in alkali-treated ground sepiolite, was catalytically less active than the nanocrystalline $\mathrm{Mg}(\mathrm{OH})_{2}$ particles formed in the $\mathrm{NaOH}$-activated parent sepiolite. In view of the very different textural properties of catalysts derived by alkali activation from the as-received sepiolite and from the ground samples it cannot be unequivocally concluded whether lower activity of the latter was due to the lower areal basicity, or to the diffusional limitations within their micropore system.

In summary, the results presented in this section showed that both grinding and alkali activation are important tools in shaping the basicity of sepiolite-derived catalysts and their performance in base-catalyzed reactions. Short grinding caused an increase of basicity, but upon extended treatment a fall of basicity with respect to the parent sepiolite was observed. In contrast, the $\mathrm{NaOH}$ activation always increased the basicity in comparison with the starting material. However, the results of catalytic tests demonstrated that basicity was not the only parameter controlling the course of catalytic reactions over these materials. Factors such as modification of textural properties and/or change of the phase composition occurring upon the above treatments could also influence the catalytic pattern.

Selected sepiolite materials investigated in this work were also subjected to tests of $\mathrm{CO}_{2}$ capture and the results are given in Table 4. The untreated sepiolite showed $\mathrm{CO}_{2}$-sorption capacity of $1.5 \mathrm{mmolg}^{-1}$, which is in agreement with previous reports $[12,67]$. This places sepiolite at the top of the list of natural clay mineral sorbents tested for $\mathrm{CO}_{2}$ entrapment [68]. $\mathrm{CO}_{2}$ sorption by raw sepiolite was attributed primarily to physisorption within the network of structural micropores. Grinding evidently worsened the $\mathrm{CO}_{2}$-uptake ability, the effect easily explicable considering the collapse of the porous system in milled sepiolite. The effect of alkali activation on $\mathrm{CO}_{2}$-sorption properties differed, depending on the application of grinding pretreatment or lack thereof. This is understandable in view of different nature of phases evolving in both types of materials. Thus, the $\mathrm{NaOH}$-treated, unground sepiolite (Sep/NaOH-24 h), which was a composite of loughlinite and nanocrystalline $\mathrm{Mg}(\mathrm{OH})_{2}$, showed a poorer performance than the as-received sepiolite (Sep), due to blocking of micropores by $\mathrm{Mg}(\mathrm{OH})_{2}$ particles. In contrast, all tested alkali-treated ground samples (Sep/gr-10'/NaOH-24 h, Sep/gr-30'/NaOH-24 $\mathrm{h}$, and Sep/gr- $60^{\prime} / \mathrm{NaOH}-24 \mathrm{~h}$ ) performed better than the ground materials from which they were derived (Sep/gr-10', Sep/gr-30', and Sep/gr-60'). The improvement was especially spectacular for Sep/gr-30'/NaOH-24 h and Sep/gr-60'/NaOH-24 h, in which formation of magnesium-rich MSH phase with a well-developed microporous texture was observed. The maximum value of $\mathrm{CO}_{2}$-capture capacity, equal to $1.9 \mathrm{mmolg}^{-1}$ was observed for the Sep/gr-30'/NaOH-24 h sample. The Sep/gr- $60^{\prime} / \mathrm{NaOH}-24 \mathrm{~h}$ sample displayed a slightly lower capacity of $1.8 \mathrm{mmolg}^{-1}$, possibly due to somewhat lower contribution of micropores in the total porosity. A literature search revealed that, up to now, modification of sepiolite which aimed at boosting its $\mathrm{CO}_{2}$-sorption capacity consisted mainly in acid activation, followed by functionalization with various amines [67,69-71]. Thus, acid treated sepiolite impregnated with tetraethylenepentamine displayed a $\mathrm{CO}_{2}$-sorption capacity of $2.2 \mathrm{mmol} / \mathrm{g}$ [69]; with triethylenetetramine $1.9 \mathrm{mmol} / \mathrm{g}$ [70]; with polyethyleneimine $1.8 \mathrm{mmol} / \mathrm{g}$ [71]; while doubly functionalized by grafting with (3-aminopropyl)triethoxysilane followed by impregnation with polyethyleneimine captured $2.1 \mathrm{mmol} / \mathrm{g}$ $\mathrm{CO}_{2}$ [67]. This comparison shows that modification of sepiolite described in this work, consisting of 
grinding and $\mathrm{NaOH}$ activation, which is a simpler and cheaper procedure than immobilization of polyamines on acid-treated sepiolite, yields sorbents of comparable $\mathrm{CO}_{2}$-uptake capacity.

\section{Conclusions}

The study revealed that grinding pretreatment of natural sepiolite changed the pathway of phase transformation of this mineral upon treatment with $\mathrm{NaOH}$ solution. Thus, wet alkali activation of the as-received sepiolite led, as previously described [12], to the formation of partially desilicated loughlinite (Na-sepiolite) with a pore system blocked by nanocrystalline $\mathrm{Mg}(\mathrm{OH})_{2}$. In contrast, the ground sepiolite with strongly amorphized structure was much more susceptible to desilication and transformed into magnesium silicate hydrate phase, with $\mathrm{Mg} / \mathrm{Si}$ ratio much higher than in the parent clay, and a well-developed microporous texture. The absence of nanocrystalline $\mathrm{Mg}(\mathrm{OH})_{2}$ in alkali-treated, shortly ground sepiolite was attributed to its consumption during MSH phase nucleation. On the other hand, in the most strongly ground and desilicated sample, not all $\mathrm{Mg}$ could be accommodated by the MSH phase, and the excess formed well crystalline $\mathrm{Mg}(\mathrm{OH})_{2}$.

${ }^{29} \mathrm{Si}$ MAS NMR analysis identified a different mechanism of desilication in the as-received and the ground sepiolite. In the former, preferential leaching of Si from the center of structural ribbons occurred, in the latter a facile loss of Si from edge positions was additionally observed, pointing to ribbon-ribbon linkages as particularly prone to milling-induced structural damage.

Results of catalytic tests showed that both grinding and alkali activation are important tools in shaping the basicity of sepiolite-derived catalysts and their performance in base-catalyzed reactions. In all cases treatment with $\mathrm{NaOH}$ led to enhancement of basicity with respect to the parent material. The effect of grinding depended on the extent of treatment and caused an increase of basicity for shortand a decrease for long-milling. However, the observed catalytic trends depended not only on surface basicity, but were also influenced by large differences in textural properties and phase composition of the alkali treated products.

Joint grinding and alkali activation proved a simple and effective method for boosting $\mathrm{CO}_{2}$-sorption capacity of sepiolite, and the resulting material performed in a manner comparable to amine functionalized, acid-activated sepiolite sorbents.

Author Contributions: Materials synthesis, investigation, text editing, A.W.; development of experimental methodologies, investigation, text editing, R.K.; investigation, text editing, J.K.-C., B.D.N., D.D., A.M., Z.O., A.T. and A.K.; conceptualization, supervision, writing, reviewing and editing, K.B.; conceptualization, supervision, writing, reviewing and editing, E.M.S. All authors contributed to the interpretation of results. All authors have read and agreed to the published version of the manuscript.

Funding: Part of this work was supported financially by the statutory research fund of ICSC PAS (Jerzy Haber Institute of Catalysis and Surface Chemistry, Polish Academy of Sciences). Procedures for basicity measurements and catalytic testing were developed within the project financed by the National Science Centre, Poland (OPUS, UMO-2017/27/B/ST5/01834). Development of the methodology for $\mathrm{CO}_{2}$-capture measurement was funded by the National Science Centre, Poland, within the project OPUS, UMO-2017/25/B/ST10/00768. A.W. was partly supported by the EU Project POWR.03.02.00-00-I004/16.

Conflicts of Interest: The authors declare no conflict of interest. The funders had no role in the design of the study; in the collection, analyses, or interpretation of data; in the writing of the manuscript, or in the decision to publish the results.

\section{References}

1. Pérez-Rodríguez, J. Transformation of clay minerals on grinding: A review. In Applied Study of Cultural Heritage and Clays; Pérez-Rodríguez, J., Ed.; Servicio Publicaciones del CSIC: Madrid, Spain, 2003; pp. 425-444.

2. Tole, K.; Habermehl-Cwirzen, K.; Cwirzen, A. Mechanochemical activation of natural clay minerals: An alternative to produce sustainable cementitious binders-Review. Miner. Petrol. 2019, 113, 449-462. [CrossRef]

3. Komadel, P. Acid Activated Clays: Materials in Continuous Demand. Appl. Clay Sci. 2016, 131, 84-99. [CrossRef] 
4. Ono, Y.H.; Hattori, H. Solid Base Catalysis; Springer Series in Chemical Physics; Springer: Berlin/Heidelberg, Germany; Tokyo Institute of Technology Press: Tokyo, Japan, 2012.

5. Avhad, M.R.; Marchetti, J.M. Innovation in solid heterogeneous catalysis for the generation of economically viable and ecofriendly biodiesel: A review. Catal. Rev. 2016, 58, 157-208. [CrossRef]

6. Choi, S.; Drese, J.H.; Jones, C.W. Adsorbent materials for carbon dioxide capture from large anthropogenic point sources. ChemSusChem 2009, 2, 796-854. [CrossRef] [PubMed]

7. Martín-Aranda, R.M.; Vicente-Rodríguez, M.A.; López-Pestaña, J.M.; López-Peinado, A.J.; Jerez, A.; de López-González, J.D.; Bañares-Muñoz, M.A. Application of Basic Clays in Microwave Activated Michael Additions: Preparation of N-substituted Imidazoles. J. Mol. Catal. A 1997, 124, 115-121. [CrossRef]

8. Soetaredjo, F.E.; Ayucitra, A.; Ismadji, S.; Maukar, A.L. KOH/bentonite Catalysts for Transesterification of Palm Oil to Biodiesel. Appl. Clay Sci. 2011, 53, 341-346. [CrossRef]

9. Boz, N.; Degirmenbasi, N.; Kalyon, D.M. Transesterification of Canola Oil to Biodiesel Using Calcium Bentonite Functionalized with K Compounds. Appl. Catal. B 2013, 138-139, 236-242. [CrossRef]

10. Alves, H.J.; da Rocha, A.M.; Monteiro, M.R.; Moretti, C.; Cabrelon, M.D.; Schwengber, C.A.; Milinsk, M.C. Treatment of Clay with KF: New Solid Catalyst for Biodiesel Production. Appl. Clay Sci. 2014, 91, 98-104. [CrossRef]

11. Olszówka, J.; Karcz, R.; Napruszewska, B.; Bielańska, E.; Dula, R.; Krzan, M.; Nattich-Rak, M.; Socha, R.P.; Klimek, A.; Bahranowski, K.; et al. Magnesium and/ or calcium-containing natural minerals as ecologically friendly catalysts for the Baeyer-Villiger oxidation of cyclohexanone with hydrogen peroxide. Appl. Catal. A 2016, 509, 52-65. [CrossRef]

12. Walczyk, A.; Michalik, A.; Napruszewska, B.D.; Kryściak-Czerwenka, J.; Karcz, R.; Duraczyńska, D.; Socha, R.P.; Olejniczak, Z.; Gawel, A.; Klimek, A.; et al. New insight into the phase transformation of sepiolite upon alkali activation: Impact on composition, structure, texture, and catalytic/sorptive properties. Appl. Clay Sci. 2020, 195, 105740. [CrossRef]

13. Olszówka, J.E.; Karcz, R.; Michalik-Zym, A.; Napruszewska, B.D.; Bielańska, E.; Kryściak-Czerwenka, J.; Socha, R.P.; Nattich-Rak, M.; Krzan, M.; Klimek, A.; et al. Effect of grinding on the physico-chemical properties of $\mathrm{Mg}-\mathrm{Al}$ hydrotalcite and its performance as a catalyst for Baeyer-Villiger oxidation of cyclohexanone. Catal. Today 2019, 333, 147-153. [CrossRef]

14. Galan, E. Properties and Applications of Palygorskite-sepiolite. Clays Clay Miner. 1996, 31, $443-453$. [CrossRef]

15. Preisinger, A. X-ray Study of the Structure of Sepiolite. Clays Clay Miner. 1959, 6, 61-67. [CrossRef]

16. Post, J.E.; Bish, D.L.; Heaney, P. Synchrotron Powder X-ray Diffraction Study of the Structure and Dehydration Behavior of Sepiolite. Am. Miner. 2007, 92, 91-97. [CrossRef]

17. Giustetto, R.; Levy, D.; Wahyudi, O.; Ricchiardi, G.; Vitillo, J.G. Crystal Structure Refinement of a Sepiolite/Indigo Maya Blue Pigment Using Molecular Modelling and Synchrotron Diffraction. Eur. J. Miner. 2011, 23, 449-466. [CrossRef]

18. Cornejo, J.; Hermosin, M.C. Structural alteration of sepiolite by dry grinding. Clay Miner. 1988, 23, $391-398$. [CrossRef]

19. Vucelic, D.; Simic, D.; Kovacevic, O.; Dojinovic, M.; Mitrovic, M. The effects of grinding on the physicochemical characteristics of white sepiolite from Golesh. J. Serb. Chem. Soc. 2003, 67, 197-211. [CrossRef]

20. Kojdecki, M.A.; Bastida, J.; Pardo, P.; Amorós, P. Crystalline microstructure of sepiolite influenced by grinding. J. Appl. Crystallogr. 2005, 38, 888-899. [CrossRef]

21. Maqueda, C.; dos Santos Afonso, M.; Morillo, E.; Torres Sánchez, R.M.; Perez-Sayago, M.; Undabeytia, T. Adsorption of diuron on mechanically and thermally treated montmorillonite and sepiolite. Appl. Clay Sci. 2013, 72, 175-183. [CrossRef]

22. Boudriche, L.; Chamayou, A.; Calvet, R.; Hamdi, B.; Balard, H. Influence of different dry milling processes on the properties of an attapulgite clay, contribution of inverse gas chromatography. Powder Technol. 2014, 254, 352-363. [CrossRef]

23. Karcz, R.; Olszówka, J.E.; Napruszewska, B.D.; Kryściak-Czerwenka, J.; Serwicka, E.M.; Klimek, A.; Bahranowski, K. Combined $\mathrm{H}_{2} \mathrm{O}_{2}$ /nitrile/bicarbonate system for catalytic Baeyer-Villiger oxidation of cyclohexanone to $\varepsilon$-caprolactone over Mg-Al hydrotalcite catalysts. Catal. Commun. 2019, 132, 105821. [CrossRef]

24. Opoczky, L. Fine Grinding and Agglomeration of Silicates. Powder Technol. 1977, 17, 1-7. [CrossRef] 
25. Anthony, J.W.; Bideaux, R.A.; Bladh, K.W.; Nichols, M.C. Handbook of Mineralogy; Mineralogical Society of America: Chantilly, VA, USA, 2001; Available online: http://www.handbookofmineralogy.org/ (accessed on 4 July 2020).

26. Cole, W.F.A. Crystalline hydrated magnesium silicate formed in the breakdown of a concrete sea-wall. Nature 1953, 171, 354-355. [CrossRef]

27. Bernard, E.; Lothenbach, B.; Rentsch, D.; Pochard, I.; Dauzères, A. Formation of magnesium silicate hydrates (M-S-H). Phys. Chem. Earth 2017, 99, 142-157. [CrossRef]

28. Tonelli, M.; Martini, F.; Calucci, L.; Fratini, E.; Geppi, M.; Ridi, F.; Borsacchi, S.; Baglioni, P. Structural characterization of magnesium silicate hydrate: Towards the design of eco-sustainable cements. Dalton Trans. 2016, 45, 3294-3304. [CrossRef]

29. Cornu, D.; Lin, L.; Daou, M.M.; Jaber, M.; Krafft, J.-M.; Herledan, V.; Laugel, G.; Millot, Y.; Lauron-Pernot, H. Influence of acid base properties of $\mathrm{Mg}$ based catalysts in transesterification. Role of Magnesium Silicate Hydrate formation. Catal. Sci. Technol. 2017, 7, 1701-1712. [CrossRef]

30. Nied, D.; Enemark-Rasmussen, K.; L’Hopital, E.; Skibsted, J.; Lothenbach, B. Properties of magnesium silicate hydrates (M-S-H). Cem. Concr. Res. 2016, 79, 323-332. [CrossRef]

31. Brew, D.R.M.; Glasser, F.P. Synthesis and characterisation of magnesium silicate hydrate gels. Cem. Concr. Res. 2005, 35, 85-98. [CrossRef]

32. Bernard, E.; Lothenbach, B.; Pochard, I.; Cau-dit-Coumes, C. Alkali binding by magnesium silicate hydrates. J. Am. Ceram. Soc. 2019, 192, 6322-6336. [CrossRef]

33. Roosz, C.; Grangeon, S.; Blanc, P.; Montouillout, V.; Lothenbach, B.; Henocq, P.; Giffaut, E.; Vieillard, P.; Gaboreau, S. Crystal structure of magnesium silicate hydrates (MSH): The relation with 2:1 Mg-Si phyllosilicates. Cem. Concr. Res. 2015, 73, 228-237. [CrossRef]

34. Galan, E.; Castillo, A. Palygorskite-Sepiolite, Occurrence, Genesis and Uses. In Developments in Sedimentology; Singer, A., Galan, E., Eds.; Elsevier: Amsterdam, The Netherlands, 1984; Volume 37, pp. 87-124.

35. Mulders, J.J.P.; Oelkers, E.H. An experimental study of sepiolite dissolution rates and mechanisms at $25^{\circ} \mathrm{C}$. Geochim. Cosmochim. Acta 2020, 270, 296-312. [CrossRef]

36. Prost, R. Infrared Study of the Interactions Between the Different Kinds of Water Molecules Present in Sepiolite. Spectrochim. Acta 1975, 31A, 1497-1499. [CrossRef]

37. Serna, C.; Ahlrichs, J.L.; Serratosa, J.M. Folding in Sepiolite Crystals. Clays Clay Miner. 1975, 23, $452-457$. [CrossRef]

38. Yariv, S. Infrared Evidence for the Occurrence of SiO Groups with Double-bond Character in Antigorite, Sepiolite and Palygorskite. Clay Miner. 1986, 21, 925-936. [CrossRef]

39. Vicente-Rodríguez, M.A.; Suarez, M.; Bañares-Muñoz, M.A.; Lopez-Gonzalez, J.D.D. Comparative FT-IR Study of the Removal and Structural Modifications during Acid Silicates of Octahedral Cations Treatment of Several Silicates. Spectrochim. Acta 1996, 52, 1685-1694. [CrossRef]

40. Frost, R.L.; Locos, O.B.; Ruan, J.; Kloprogge, J.T. Near-infrared and Mid-infrared Spectroscopic Study of Sepiolites and Palygorskites. Vib. Spectrosc. 2001, 27, 1-13. [CrossRef]

41. Mora, M.; López, M.I.; Carmona, M.A.; Jiménez-Sanchidrián, C.; Ruiz, J.R. Study of the Thermal Decomposition of a Sepiolite by Mid- and Near-infrared Spectroscopies. Polyhedron 2010, 29, 3046-3051. [CrossRef]

42. Bukas, V.J.; Tsampodimou, M.; Gionis, V.; Chryssikos, G.D. Synchronous ATR Infrared and NIR-spectroscopy Investigation of Sepiolite Upon Drying. Vib. Spectrosc. 2013, 68, 51-60. [CrossRef]

43. Lescano, L.; Castillo, L.; Marfil, S.; Barbosa, S.; Maiza, P. Alternative Methodologies for Sepiolite Defibering. Appl. Clay Sci. 2014, 95, 378-382. [CrossRef]

44. Madejová, J.; Gates, W.P.; Petit, S. IR spectra of clay minerals. In Infrared and Raman Spectroscopies of Clay Minerals. Developments in Clay Science; Gates, W.P., Klopproge, J.T., Madejová, J., Bergaya, F., Eds.; Elsevier: Amsterdam, The Netherlands, 2017; Volume 8, pp. 107-149.

45. Gunasekaran, S.; Anbalagan, G.; Pandi, S. Raman and Infrared Spectra of Carbonates of Calcite Structure. J. Raman Spectrosc. 2006, 37, 892-899. [CrossRef]

46. Olszówka, J.E.; Karcz, R.; Bielańska, E.; Kryściak-Czerwenka, J.; Napruszewska, B.D.; Sulikowski, B.; Socha, R.P.; Bahranowski, K.; Olejniczak, Z.; Serwicka, E.M. New Insight into the Preferred Valency of Interlayer Anions in Hydrotalcite-like Compounds: The Effect of Mg/Al Ratio. Appl. Clay Sci. 2018, 155, 84-94. [CrossRef] 
47. McKeown, D.A.; Post, J.E.; Etz, E.S. Vibrational Analysis of Palygorskite and Sepiolite. Clays Clay Miner. 2002, 50, 667-680. [CrossRef]

48. Mendelovici, E. Selective mechanochemical reactions on dry grinding structurally different silicates. J. Mater. Sci. Lett. 2001, 20, 81-83. [CrossRef]

49. Gates, W.P.; Anderson, J.S.; Raven, M.D.; Churchman, G.J. Mineralogy of a bentonite from Miles, Queensland, Australia and characterisation of its acid activation products. Appl. Clay Sci. 2002, 20, 189-197. [CrossRef]

50. Zhang, T.; Zou, J.; Wang, B.; Wu, Z.; Jia, Y.; Cheeseman, C.R. Characterization of Magnesium Silicate Hydrate (MSH) Gel Formed by Reacting MgO and Silica Fume. Materials 2018, 11, 909. [CrossRef]

51. Walling, S.A.; Kinoshita, H.; Bernal, S.A.; Colliera, N.C.; Provis, J.L. Structure and properties of binder gels formed in the system $\mathrm{Mg}(\mathrm{OH})_{2}-\mathrm{SiO}_{2}-\mathrm{H}_{2} \mathrm{O}$ for immobilisation of Magnox sludge. Dalton Trans. 2015, 44, 8126-8137. [CrossRef]

52. Zhang, Y.; Li, Y.; Dai, Y.; Xu, Y. Hydration evolution of MgO-SiO2 slurries in the presence of sodium metasilicate. Ceram. Int. 2018, 44, 6626-6633. [CrossRef]

53. Lippmaa, E.; Magi, M.; Samoson, A.; Engelhardt, G.; Grimmer, A.R. Structural studies of silicates by solid-state high-resolution ${ }^{29}$ Si NMR. J. Am. Chem. Soc. 1980, 102, 4489-4893. [CrossRef]

54. D'Espinose de la Caillerie, J.B.; Fripiat, J.J. A Reassessment of the ${ }^{29}$ Si MAS-NMR Spectra of Sepiolite and Aluminated Sepiolite. Clay Miner. 1994, 29, 313-318. [CrossRef]

55. Weir, M.R.; Kuang, W.; Facey, G.A.; Detellier, C. Solid-state Nuclear Magnetic Resonance Study of Sepiolite and Partially Dehydrated Sepiolite. Clays Clay Miner. 2002, 50, 240-247.

56. Sanz, J.; Massiot, D. Nuclear magnetic resonance spectroscopy. In Handbook of Clay Science. Part B; Bergaya, F., Lagaly, G., Eds.; Elsevier: Amsterdam, The Netherlands; Oxford, UK, 2013; pp. 233-274.

57. Bernard, E.; Lothenbach, B.; Chlique, C.; Wyrzykowski, M.; Dauzères, A.; Pochard, I.; Cau-Dit-Coumes, C. Characterization of magnesium silicate hydrate (M-S-H). Cem. Concr. Res. 2019, 116, 309-330. [CrossRef]

58. Bautista, F.M.; Campelo, J.M.; Luna, D.; Marinas, J.M.; Quirós, R.A.; Romero, A.A. Screening of Amorphous Metal-phosphate Catalysts for the Oxidative Dehydrogenation of Ethylbenzene to Styrene. Appl. Catal. B Environ. 2007, 70, 611-620. [CrossRef]

59. Nielsen, A.T.; Houlihan, W.J. The Aldol Condensation. Org. React. 1968, 16, 1-438.

60. Kunkes, E.L.; Simonetti, D.A.; West, R.M.; Serrano-Ruiz, J.C.; Gärtner, C.A.; Dumesic, J.A. Catalytic Conversion of Biomass to Monofunctional Hydrocarbons and Targeted Liquid-fuel Classes. Science 2006, 322, 417-421. [CrossRef] [PubMed]

61. Climent, M.J.; Corma, A.; Fornes, V.; Guil-Lopez, R.; Iborra, S. Aldol Condensations on Solid Catalysts: A Cooperative Effect between Weak Acid and Base Sites. Adv. Synth. Catal. 2002, 344, 1090-1096. [CrossRef]

62. Snell, R.W.; Combs, E.; Shanks, B.H. Aldol Condensations Using Bio-oil Model Compounds: The Role of Acid-Base Bi-functionality. Top. Catal. 2010, 53, 1248-1253. [CrossRef]

63. Brunelli, N.A.; Venkatasubbaiah, K.; Jones, C.W. Cooperative Catalysis with Acid-Base Bifunctional Mesoporous Silica: Impact of Grafting and Co-condensation Synthesis Methods on Material Structure and Catalytic Properties. Chem. Mater. 2012, 24, 2433-2442. [CrossRef]

64. Labet, M.; Thielemans, W. Synthesis of polycaprolactone: A review. Chem. Soc. Rev. 2009, 38, 3484-3504. [CrossRef]

65. Ten Brink, G.J.; Arends, I.W.C.E.; Sheldon, R.A. The Baeyer-Villiger Reaction: New Developments toward Greener Procedures. Chem. Rev. 2004, 104, 4105-4124. [CrossRef]

66. Richardson, D.E.; Yao, H.; Frank, K.M.; Bennett, D.A. Equilibria, Kinetics, and Mechanism in the Bicarbonate Activation of Hydrogen Peroxide: Oxidation of Sulfides by Peroxymonocarbonate. J. Am. Chem. Soc. 2000, 122, 1729-1739. [CrossRef]

67. Cecilia, J.A.; Vilarrasa-García, E.; Cavalcante, C.L.; Azevedo, D.C.S.; Franco, F.; Rodríguez-Castellón, E. Evaluation of Two Fibrous Clay Minerals (Sepiolite and Palygorskite) for $\mathrm{CO}_{2}$ Capture. J. Environ. Chem. Eng. 2018, 6, 4573-4587. [CrossRef]

68. Chouikhi, N.; Cecilia, J.A.; Vilarrasa-García, E.; Besghaier, S.; Chlendi, M.; Franco Duro, F.I.; Rodriguez Castellon, E.; Bagane, M. $\mathrm{CO}_{2}$ Adsorption of Materials Synthesized from Clay Minerals: A Review. Minerals 2019, 9, 514. [CrossRef]

69. Irani, M.; Fan, M.; Ismail, H.; Tuwati, A.; Dutcher, B.; Russell, A.G. Modified nanosepiolite as an inexpensive support of tetraethylenepentamine for $\mathrm{CO}_{2}$ sorption. Nano Energy 2015, 11, 235-246. [CrossRef] 
70. Yuan, M.; Gao, G.; Hu, X.; Luo, X.; Huang, Y.; Jin, B.; Liang, Z. Premodified Sepiolite Functionalized with Triethylenetetramine as an Effective and Inexpensive Adsorbent for $\mathrm{CO}_{2}$ Capture. Ind. Eng. Chem. Res. 2018, 57, 6189-6200. [CrossRef]

71. Vilarrasa-García, E.; Cecilia, J.; Bastos-Neto, M.; Cavalcante, C.; Azevedo, D.; Rodríguez-Castellon, E. Microwave-assisted nitric acid; treatment of sepiolite and functionalization with polyethylenimine applied to $\mathrm{CO}_{2}$ capture and $\mathrm{CO}_{2} / \mathrm{N}_{2}$ separation. Appl. Surf. Sci. 2017, 410, 315-325. [CrossRef]

(c)

(C) 2020 by the authors. Licensee MDPI, Basel, Switzerland. This article is an open access article distributed under the terms and conditions of the Creative Commons Attribution (CC BY) license (http://creativecommons.org/licenses/by/4.0/). 